\title{
Climatological Characteristics of Arctic and Antarctic Surface-Based Inversions*
}

\author{
YeHui ZHANG AND DiAn J. SEIDEL \\ NOAA/Air Resources Laboratory, Silver Spring, Maryland \\ JEAN-CHRISTOPHE GOLAZ \\ NOAA/Geophysical Fluid Dynamics Laboratory, Princeton, New Jersey \\ Clara Deser and Robert A. TOMAS \\ NCAR Climate and Global Dynamics Division, Boulder, Colorado
}

(Manuscript received 16 August 2010, in final form 20 May 2011)

\begin{abstract}
Surface-based inversions (SBIs) are frequent features of the Arctic and Antarctic atmospheric boundary layer. They influence vertical mixing of energy, moisture and pollutants, cloud formation, and surface ozone destruction. Their climatic variability is related to that of sea ice and planetary albedo, important factors in climate feedback mechanisms. However, climatological polar SBI properties have not been fully characterized nor have climate model simulations of SBIs been compared comprehensively to observations. Using 20 years of twice-daily observations from 39 Arctic and 6 Antarctic radiosonde stations, this study examines the spatial and temporal variability of three SBI characteristic-frequency of occurrence, depth (from the surface to the inversion top), and intensity (temperature difference over the SBI depth)—and relationships among them. In both polar regions, SBIs are more frequent, deeper, and stronger in winter and autumn than in summer and spring. In the Arctic, these tendencies increase from the Norwegian Sea eastward toward the East Siberian Sea, associated both with (seasonal and diurnal) variations in solar elevation angle at the standard radiosonde observation times and with differences between continental and maritime climates. Two state-of-the-art climate models and one reanalysis dataset show similar seasonal patterns and spatial distributions of SBI properties as the radiosonde observations, but with biases in their magnitudes that differ among the models and that are smaller in winter and autumn than in spring and summer. SBI frequency, depth, and intensity are positively correlated, both spatially and temporally, and all three are anticorrelated with surface temperature.
\end{abstract}

\section{Introduction}

Surface-based inversions (SBIs), where atmospheric temperature increases with height from the surface, are a frequent feature of the atmospheric boundary layer in the Arctic and Antarctic. They are found in more than

\footnotetext{
* Supplemental information related to this paper is available at the Journals Online Web site: http://dx.doi.org/10.1175/ 2011JCLI4004.s1.

Corresponding author address: Dr. Dian Seidel, NOAA Air Resources Laboratory (R/ARL), 1315 East West Highway, Silver Spring, MD 20910.

E-mail: dian.seidel@noaa.gov
}

$\sim 40 \%$ of nighttime radiosonde observations and more than $\sim 20 \%$ of daytime observations at stations poleward of 60 degrees latitude and occur more often in winter than summer (Seidel et al. 2010).

Two mechanisms dominate the formation of low-level and surface-based inversions (Busch et al. 1982 and references therein; Bradley et al. 1992). One is imbalance between outgoing longwave radiation from the surface and downwelling solar and infrared radiation, leading to surface cooling, common in winter and at night. The other mechanism is advection of warm air over a cooler surface layer, which can occur at any time. Surfacebased and low-level inversions in polar regions may also be affected by subsidence processes, radiative properties of clouds and precipitating ice crystals, turbulent mixing, 
surface fluxes of heat and moisture, etc. (Busch et al. 1982; Curry 1983; Kahl 1990; Kahl et al. 1992; Serreze et al. 1992), and they, in turn, may influence vertical mixing of energy, moisture and pollutants, cloud formation, and surface destruction of ozone (Andreas 1980; Andreas and Murphy 1986; Bowling 1986; Barrie et al. 1988; Kahl 1990; Boé et al. 2009). Recent studies (Kay and Gettelman 2009; Deser et al. 2010; Mernild and Liston 2010; Pavelsky et al. 2011) have linked SBIs and low-level inversions in both hemispheres to variability of sea ice and thus planetary albedo, an important factor in climate feedback mechanisms and therefore in determining climate sensitivity to changes in radiative forcing.

This study uses radiosonde observations to investigate the climatology of SBIs in the polar regions. It builds upon early work by Hosler (1961), who examined the climatology of low-level inversions [based below 500 feet $(\sim 150 \mathrm{~m})]$ over the contiguous United States. Later studies also employed radiosonde data to study low-level and surface-based inversions over portions of the Arctic (Kahl 1990; Kahl et al. 1992; Serreze et al. 1992; Bradley et al. 1992, 1993; Walden et al. 1996; Kadygrov et al. 1999; Bourne et al. 2010) and Antarctic (Phillpot and Zillman 1970; Stone and Kahl 1991; Connolley 1996; Mahesh et al. 1997; Andreas et al. 2000). However, either by design or because of data limitations, these analyses have restricted spatial and temporal scope and generally have not addressed diurnal variations of inversion characteristics (but see Malingowski et al. 2010 on diurnal SBI development over Fairbanks).

Several recent studies have examined the climate variability of the Arctic boundary layer using satellite observations (Liu and Key 2003; Kay and Gettelman 2009; Devasthale et al. 2010; Pavelsky et al. 2011), but these have limitations for detailed examination of SBIs. Moderate Resolution Imaging Spectroradiometer (MODIS) data are limited to clear-sky conditions to identify SBIs, and inversions are defined based on brightness temperature differences between two channels (Liu and Key 2003) rather than from the surface to the inversion top. Similarly, Atmospheric Infrared Sounder (AIRS) data have limited vertical resolution compared with radiosonde observations, and investigators have defined inversions using temperature differences between fixed pressure levels (925 and 1000 hPa, Kay and Gettelman 2009; 850 and $1000 \mathrm{hPa}$, Pavelsky et al. 2011). Here, we use the full vertical resolution of radiosonde observations to more precisely identify the SBI layer and quantify its structure.

The main goals of this paper are 1) to develop a comprehensive climatology of SBI characteristics, including seasonal, diurnal and spatial variations, for both polar regions and 2) for the first time, to compare SBI properties derived from two state-of-the-art climate models and one reanalysis dataset with the observational results. Section 2 describes the datasets and methodology and discusses sources of uncertainty in quantitative estimates of SBI properties and their climatological statistics. Section 3 presents the observational characteristics of SBIs and comparison with the reanalysis and climate models, for both the Arctic and (to a lesser extent, due to data limitations) the Antarctic. Some results pertinent to sections 2 and 3 are provided as supplemental material. The final section 4 summarizes our main findings. To facilitate comparison of our results with other climate model simulations and observational data, the complete SBI datasets used in this analysis are also provided as supplemental material (http://dx.doi.org/10.1175/2011JCLI4004.s1).

\section{Data and methods}

\section{a. Radiosonde observations}

Radiosonde data from an enhanced version of the Integrated Global Radiosonde Archive (IGRA; Durre et al. 2006; Durre and Yin 2008) for the 20-yr period 1990-2009 form the basis of this analysis. The IGRA is a quality-controlled compilation of radiosonde observations from the global network of more than 1500 stations and includes the observed temperature, geopotential height, humidity, wind direction, and wind speed at standard (mandatory) levels (including the surface level and 1000, 925, 850, 700, $500 \mathrm{hPa}$, etc.) and significant levels at which the sounding deviates from linearity (in logarithm of pressure) between two standard levels. To ensure a representative climatology, we require at least $50 \%$ of the expected number of soundings at a given observation time (0000 or 1200 UTC) for Arctic stations. For Antarctic stations, where data records are less complete, we relax the threshold to $30 \%$, although more than half of Antarctic stations have reporting frequencies exceeding $50 \%$.

\section{b. Climate models}

The observations are compared with simulations from the following two climate models: the new National Oceanic and Atmospheric Administration (NOAA) Geophysical Fluid Dynamics Laboratory Atmosphere Model version 3 (GFDL AM3; Donner et al. 2011) and the National Center for Atmospheric Research (NCAR) Community Atmosphere Model version 3 (CAM3; Collins et al. 2006) coupled to the Community Land Model version 3 (CLM3; Oleson et al. 2004). The spatial resolution of the GFDL AM 3 is $2^{\circ}$ latitude $\times 2.5^{\circ}$ longitude, with 48 vertical levels from the surface to the stratosphere, 15 below $500 \mathrm{hPa}$ and 9 in the lowest $1.5 \mathrm{~km}$. The NCAR CAM3/ CLM3 has approximately $1.4^{\circ}$ horizontal resolution 


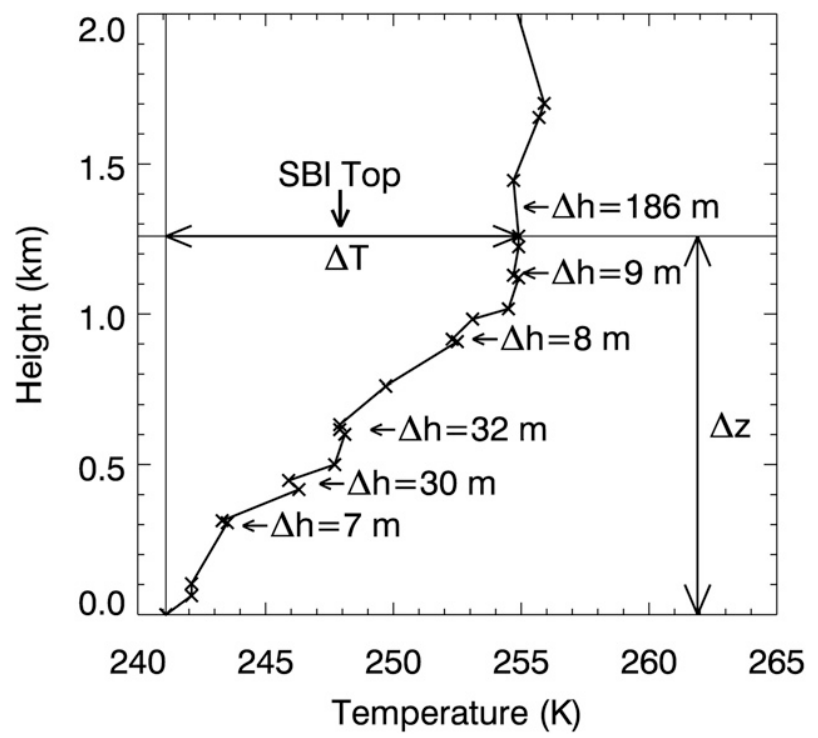

FIG. 1. Sample temperature profile from Alert, Canada $\left(82^{\circ} \mathrm{N}\right.$, $62^{\circ} \mathrm{W}$ ), at $1200 \mathrm{UTC} 14 \mathrm{Feb} 2009$ showing a surface-based inversion and its depth $\Delta z$ and intensity $\Delta T$. Thin embedded noninversion layers (temperature decrease with height) are indicated, and $\Delta h$ values are their thicknesses.

and 26 vertical levels (Collins et al. 2006), 8 below $500 \mathrm{hPa}$ and about 4 in the lowest $1.5 \mathrm{~km}$. Both models use $\sigma$ (i.e., $p / p_{s}$, where $p$ is pressure, and $p_{s}$ is surface pressure) as a vertical coordinate. The lowest atmospheric level is at $\sigma=0.9961 \mathrm{in} \mathrm{GFDL} \mathrm{AM3} \mathrm{and} \mathrm{at} \sigma=0.9925$ for NCAR CAM3. Unlike previous studies of climate model representations of SBIs based on monthly-mean model output (Boé et al. 2009; Deser et al. 2010), SBI statistics in this study are based on instantaneous profiles saved every $6 \mathrm{~h}(0000,0600,1200,1800$ UTC) from both models.

\section{c. Reanalysis data}

Because of the irregular and sparse coverage of the radiosonde network, especially over the Arctic Ocean and the interior of the Antarctic continent, we augment the radiosonde observations with reanalysis data from the European Center for Medium-Range Weather Forecasts (ECMWF) Reanalysis (ERA-Interim; Simmons et al. 2007). ERA-Interim is an updated and improved version of the earlier 40-yr ECMWF Re-Analysis (ERA-40; Uppala et al. 2005), with finer vertical resolution (37 versus 23 levels from 1000 to $1 \mathrm{hPa}$ ) and finer horizontal resolution $\left(1.5^{\circ}\right.$ versus $\left.2.5^{\circ}\right)$. ERA-Interim data have 16 levels below $500 \mathrm{hPa}$ and 6-hourly sampling $(0000,0600$, 1200, 1800 UTC). The surface level in the ERA-Interim data is at $2 \mathrm{~m}$, comparable to the radiosonde surface observation height (instrument shelter height). Although other reanalyses are now available, including the Japanese
Meteorological Service 25-yr reanalysis (JRA-25) (Onogi et al. 2007) and the National Centers for Environmental Prediction-National Center for Atmospheric Research (NCEP-NCAR) reanalysis (Kalnay et al. 1996), we employ ERA because of its smaller temperature errors (Graversen et al. 2008) and reasonable representation of observed inversion properties (Tjernström and Graversen 2009). In the course of this research, we chose ERAInterim over ERA-40, in large part because we found ERA-Interim to be in better agreement with the radiosonde depiction of SBIs (particularly their depth) in regions of good radiosonde coverage. Elsewhere, it is likely more strongly influenced by the assimilation model.

\section{d. Surface-based inversion definition and analysis methods}

For all four datasets, SBIs are identified from temperature profile data using Kahl's (1990) algorithm, which scans from the surface upward to $500 \mathrm{hPa}$ to find cases with temperature increasing with altitude. The inversion top is defined as the bottom of the first layer in which temperature decreases with altitude, but thin $(<100 \mathrm{~m})$ noninversion layers, with temperature decreasing with height, are ignored if they are embedded within a deeper inversion layer. Soundings are considered to be unsuitable for analysis if the surface level is missing, there are fewer than 10 upper-air data levels from surface to $500 \mathrm{hPa}$, or the temperature difference across the inversion exceeds 40 K (Serreze et al. 1992). This definition represents a true inversion layer (from the surface to the inversion top), which is different from defining inversion strength as a temperature difference between two prespecified levels or heights in the boundary layer (Hudson and Brandt 2005; Kay and Gettelman 2009; Pavelsky et al. 2011).

Two parameters give a quantitative measure of each SBI: SBI depth [altitude above ground level (AGL) of the SBI top $\Delta z$ ] and SBI intensity (temperature difference across the inversion layer $\Delta T$ ). An example, using the 1200 UTC 14 February 2009 sounding from Alert, on the Canadian Arctic archipelago, is shown in Fig. 1. Using the definitions above, we find the SBI top at $1259 \mathrm{~m}$ AGL, with SBI depth $\Delta z$ and intensity $\Delta T$ of $1259 \mathrm{~m}$ and $13.8 \mathrm{~K}$, respectively. This profile also reveals several thin $(7,30,32,8$, and $9 \mathrm{~m})$ noninversion layers embedded within the deep SBI. Above $1259 \mathrm{~m}$, the 186-m-thick noninversion layer (exceeding the 100-m threshold) marks the top of the SBI.

For each grid point or radiosonde station, we compute frequency of SBI occurrence $(f)$ and average SBI depth and intensity for the overall dataset and separately for each season, for each month, and for 0000 and 1200 UTC 


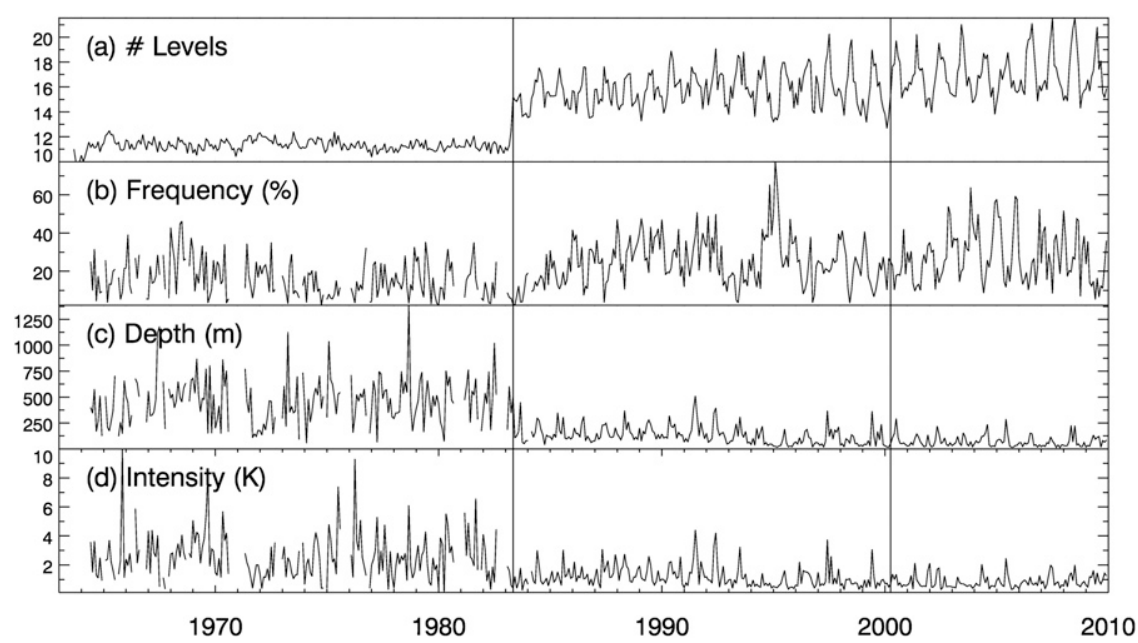

FIG. 2. Time series of monthly (a) mean number of reported data levels (surface to $500 \mathrm{hPa}$ ) and (b) surface-based inversion frequency, (c) mean SBI depth, and (d) mean SBI intensity at Jan Mayen $\left(71^{\circ} \mathrm{N}, 9^{\circ} \mathrm{W}\right)$ for $1963-2009$. Vertical lines show statistically detected changepoints in the number of levels.

( $\pm 1 \mathrm{~h}$ to account for the 1-2-h sounding duration). Following Kahl (1990) and Serreze et al. (1992), threemonth seasons are defined as January-March (Arctic winter, Antarctic summer), July-September (Arctic summer and Antarctic winter), etc.

In all comparisons of the various datasets, the models and reanalysis are sampled at 0000 and 1200 UTC to mimic the radiosondes. Comparisons of radiosonde data and the two climate models are for 1990-2007. Comparisons for radiosonde data and ERA-Interim, and analysis of radiosonde data alone, are for 1990-2009.

\section{e. Continuity and temporal homogeneity of radiosonde data}

Although radiosonde data are available in IGRA for 113 Arctic and 19 Antarctic stations, some spanning more than $50 \mathrm{yr}$, this study employs only 39 and 6 of these, respectively, and these only for 1990-2009. Many of the station records do not have continuous records. Many others are plagued by temporal inhomogeneities due to changes in radiosonde instruments and observing practices (including changes in temperature sensor, radiation corrections, balloon type, observation time, and station location) that introduce artificial changes in temperature records (Gaffen 1994).

Improvements in data-recording systems (from manual to mechanical to increasingly powerful computer-based systems) have led to steplike increases in the vertical resolution of sounding data. Walden et al. (1996) showed that the SBI time series of Bradley et al. (1992) contained temporal inhomogeneities associated with increases in the number of reported vertical levels in the soundings.
Our examination of long-term (1958-2009) Arctic and Antarctic SBI time series confirms this result (shown in Fig. 2). We employed a nonparametric statistical method (Lanzante 1996) to detect changepoints in station time series of the number of reported data levels below $500 \mathrm{hPa}$. The detected changepoints and station history metadata were then used in visual inspection of time series of SBI characteristics (frequency, depth, and intensity) to identify possible changepoints in SBI characteristics associated with detected changepoints in vertical resolution.

Data from Jan Mayen $\left(71^{\circ} \mathrm{N}, 9^{\circ} \mathrm{W}\right)$ are a good example of the effect of increasing vertical resolution on SBI characteristics (Fig. 2). The time series of mean monthly number of reported levels (surface to $500 \mathrm{hPa}$ ) has two statistically detected changepoints-one in 1983 when the average increased from 11.3 to 15.8 and the second in 2000 when it increased to 17.0 levels per sounding. The 1983 increase is associated with a simultaneous 9\% increase in $f$ (from $16 \%$ to $25 \%$ ) and even more obvious decreases in $\Delta z$ (of $325 \mathrm{~m}$, from 456 to $131 \mathrm{~m}$ ) and $\Delta T$ (of $1.3 \mathrm{~K}$, from 2.5 to $1.2 \mathrm{~K}$ ). The smaller 2000 increase in vertical resolution is associated with smaller changes in $f, \Delta z$, and $\Delta T$ (of $2 \%, 60 \mathrm{~m}$, and $0.3 \mathrm{~K}$, respectively). In this case, we consider the $f$ data homogeneous for the period following 1983 and the $\Delta z$ and $\Delta T$ following 2000 .

Examining all the Arctic and Antarctic radiosonde station SBI time series, and attempting to balance spatial sampling, data continuity, and homogeneity concerns, we limited our analysis to the 20-yr period 1990-2009. A list of stations with homogeneous SBI frequency data for this period is given in Tables S1 and S2 in the supplemental 
material, which also includes more detailed information about data availability at these stations and at the stations excluded from the analysis. Most Russian Arctic station records have gaps, and most Canadian, Greenland, and Eurasian Arctic stations are plagued by data inhomogeneities, particularly in $\Delta z$ and $\Delta T$ time series, associated with changes in sounding resolution.

The greater sensitivity of SBI depth and intensity (as compared with SBI frequency) to vertical resolution changes is probably a result of our general requirement of a minimum of 10 levels per sounding. The existence of SBIs is likely to be captured in all such soundings, in accord with World Meteorological Organization reporting requirements (WMO 2008, section 12.10.1). However, the SBI top is likely to be found at a lower level as the number of levels increases, so that $\Delta z$ and $\Delta T$ are less robust to changes in resolution. Moreover, the impact is systematic - increasing of number of levels increases the resolution of small-scale temperature fluctuations in the profile, resulting in SBI detection at lower heights with smaller temperature differences. But because the shifts in $\Delta z$ and $\Delta T$ are small relative to their mean values, section 3 includes climatological $\Delta z$ and $\Delta T$ results at all the stations with homogeneous $f$ time series, even those with inhomogeneous $\Delta z$ and $\Delta T$ time series.

\section{f. Sensitivity of surface-based inversion statistics to definition and analysis methods}

Because the SBI definition and analysis method described in section $2 \mathrm{~d}$ involve some choices that may appear somewhat arbitrary, this section explores the sensitivity of SBI climatology statistics to these choices. Below we address the following: inclusion versus omission of surface-level observations, the threshold thickness of noninversion layers allowed within the SBI, and the focus on SBIs rather than all low-level inversions (and the related issue of using instantaneous rather than time-averaged vertical profile data).

Superficially, it would seem obvious, even requisite, to include surface observations to analyze surface-based inversions. However, we questioned this, particularly for analysis of radiosonde data, which generally combine a surface observation from instruments in shelters with upper-air observations from radiosonde instrument packages. Because the shelter may not be collocated with, or at the same elevation as, the sounding launch site, it is possible to imagine temperature differences between the surface observation and the first level of radiosonde observation showing (or not showing) an SBI that is not representative of the rest of the sounding or of the conditions at the sounding location.

The sensitivity of climatological Arctic SBI parameters to inclusion or omission of surface data is shown in the supplemental material (Fig. S1). The spatial patterns of SBI frequency, depth, and intensity are very similar in both cases, but there are nonzero differences in magnitudes. The frequency differences (with surface minus without surface) range from $-9 \%$ to $23 \%$, with a median absolute difference of $4 \%$ [and interquartile range (IQR) of 10\%). SBI depth differences range from -104 to $71 \mathrm{~m}$, with a median absolute difference of $18 \mathrm{~m}$ (and 56-m IQR). SBI intensity differences range from -0.7 to $2.7 \mathrm{~K}$, with a median absolute difference of $1.0 \mathrm{~K}$ (and 1.0-K IQR). The mainly positive SBI intensity differences (larger $\Delta T$ when surface data are included) are due to the additional near-surface region of inversion thickness contributing to the overall $\Delta T$. We include surface observations in the climatological analysis below, but we recognize that this results in more intense SBIs than if we had omitted them and typical structural uncertainties of about $4 \%, 18 \mathrm{~m}$, and $1 \mathrm{~K}$ for SBI frequency, depth, and intensity, respectively.

We also examined the sensitivity of climatological SBI statistics to the tolerated thickness of noninversion layers embedded within the SBIs by testing thickness values of $1,50,100,150,200$, and $300 \mathrm{~m}$. As shown in the supplemental material (Fig. S2), for thickness thresholds of 1, 50 , and $100 \mathrm{~m}$, climatological $f, \Delta z$, and $\Delta T$ values are almost identical, with differences typically $<0.3 \%, 20 \mathrm{~m}$, and $0.1 \mathrm{~K}$, respectively. When thicker noninversion layers are allowed, we obtain higher SBI $\Delta z$ and $\Delta T$ values, as expected. For example, when the embedded layer is allowed to reach $200 \mathrm{~m}, \Delta z$ and $\Delta T$ differences (compared with $100 \mathrm{~m}$ embedded layers) can exceed $70 \mathrm{~m}$ and $0.3 \mathrm{~K}$, respectively. Given median Arctic SBI depths of about $350 \mathrm{~m}$ (section 3), the lack of sensitivity of $f, \Delta z$ and $\Delta T$ values to thickness choices of $100 \mathrm{~m}$ or less, and the precedent in literature for 100-m thickness (Kahl 1990), our analysis allows noninversion layers of $<100$-m thickness within a deeper SBI.

Lastly, we explain our focus on SBIs. Some previous studies (Kahl 1990; Kahl et al. 1992; Serreze et al. 1992; Andreas et al. 2000) of the polar boundary layer addressed all low-level temperature inversions, including both SBIs and elevated inversion layers, and found that most profiles revealed elevated inversion layers rather than SBIs. The supplemental material (Fig. S3) shows climatological frequencies of SBI and elevated inversion occurrence in the Arctic, with the latter occurring much more often than the former. The combined low-level inversion (SBI and elevated inversion) frequency is near $100 \%$. This is also the case for the Antarctic (not shown), and for the rest of the globe. Seidel et al. (2010) found that only $13 \%$ of soundings in a global (505 station) analysis of 10 years of radiosonde data showed neither SBI nor elevated inversions at or below $500 \mathrm{hPa}$. Thus, except for 

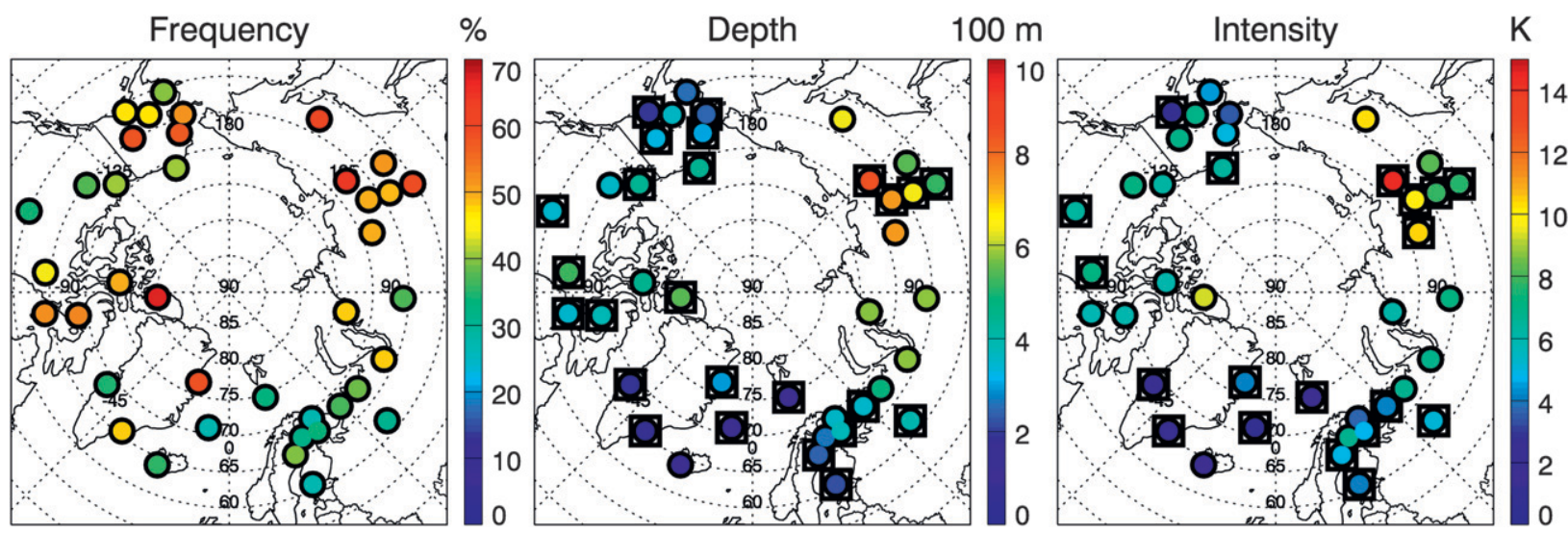

FIG. 3. Maps of mean annual SBI (left) frequency, (middle) depth, and (right) intensity over the Arctic from 39 radiosonde stations with homogeneous records for 1990-2009. Squares denote stations with inhomogeneous SBI depth and intensity time series.

regions of frequent cases of deep vertical convection, analysis of low-level inversions is, for the most part, analysis of the planetary boundary layer in general. This study isolates SBI cases because of their prominence in polar climates and their important role in limiting vertical mixing.

In addition, Walden et al. (1996) recommended the use of monthly or seasonal average profiles instead of individual profiles in inversion studies. Such an approach is a de facto combination of SBI and elevated inversion cases (as well as any cases without inversions) and so is not appropriate to analysis of SBIs. This study, therefore, relies on individual soundings rather than monthly average profile data to isolate profiles with SBIs.

\section{Results}

This section presents the climatology of SBI, first for the Arctic then for the Antarctic. For both regions, results from radiosonde observations are shown separately before being compared with reanalysis and climate model simulations.

\section{a. Observed Arctic SBI climatology}

The maps in Fig. 3 show mean SBI frequency, depth, and intensity over the Arctic. The depth and intensity averages are based on all soundings exhibiting SBIs during the period 1990-2009. The frequency results are shown only for 39 stations with temporally homogeneous records (section 2e). Depth and intensity results are presented for the same stations, including some with inhomogeneous records, but the inhomogeneities do not strongly affect the climatological results, as suggested by the similarity of results from nearby stations with homogeneous records. Corresponding maps of standard deviations of frequency, depth, and intensity are provided as supplemental material (Fig. S4). The results for stations in Alaska are in very good agreement with those of Bourne et al. (2010), who also used IGRA data to study SBI characteristics in that region of the Arctic, which instills confidence in the reproducibility of these and other climatological statistics presented here.

Median (over all Arctic stations) $f, \Delta z$, and $\Delta T$ values are $46 \%, 356 \mathrm{~m}$, and $6.1 \mathrm{~K}$, respectively. Given that radiative cooling of the surface is one of the key processes responsible for SBI formation, it is perhaps not surprising that stations closer to the North Pole, particularly in Greenland, Alaska, Canada, and Siberian Russia, experience more frequent $(f>50 \%)$, deeper $(\Delta z$ approaching $1 \mathrm{~km})$, and more intense $(\Delta T>5 \mathrm{~K}) \mathrm{SBIs}$ than lower-latitude stations. The highest frequency, $67 \%$, is at Eureka, Canada $\left(80^{\circ} \mathrm{N}, 86^{\circ} \mathrm{W}\right)$. The most intense SBIs, with climatological temperature differences $\sim 14 \pm 2 \mathrm{~K}$ (mean \pm one standard deviation), occur at the Siberian stations, most of which are in valleys (the Yana River valley), where stronger inversions are expected (Anquetin et al. 1998). The deepest and strongest SBIs are found at Verkhoyansk, Russia $\left(68^{\circ} \mathrm{N}, 133^{\circ} \mathrm{E}\right)$, where the annual SBI depth and intensity are $839 \mathrm{~m}$ and $14 \mathrm{~K}$, respectively. In contrast, the lowest SBI frequency found among these homogeneous Arctic stations, $26 \%$, is at Jan Mayen, in the Norwegian Sea $\left(71^{\circ} \mathrm{N}, 9^{\circ} \mathrm{W}\right)$. This region also has the shallowest and weakest SBIs, a feature that is likely related to the relatively high surface temperatures associated with warm North Atlantic Ocean currents.

Complementing the annual data in Fig. 3, Fig. 4 shows seasonal SBI frequency-seasonal depth and intensity maps are provided in supplementary material (Figs. S5 and S6). In general, Arctic SBIs are more frequent, deeper, and stronger in winter and, to a lesser extent, in autumn, than in spring and summer. Over Siberia, Canada, and Greenland, 


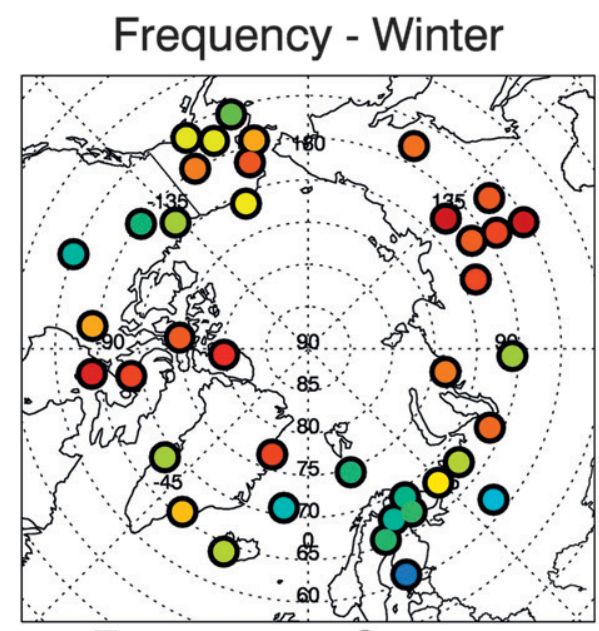

Frequency - Summer

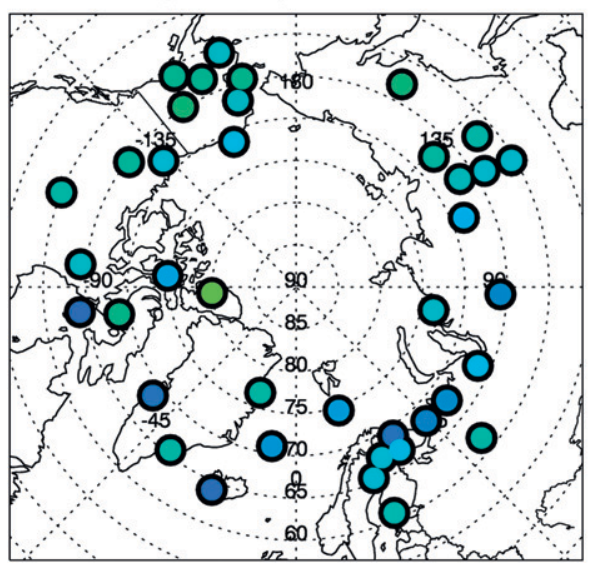

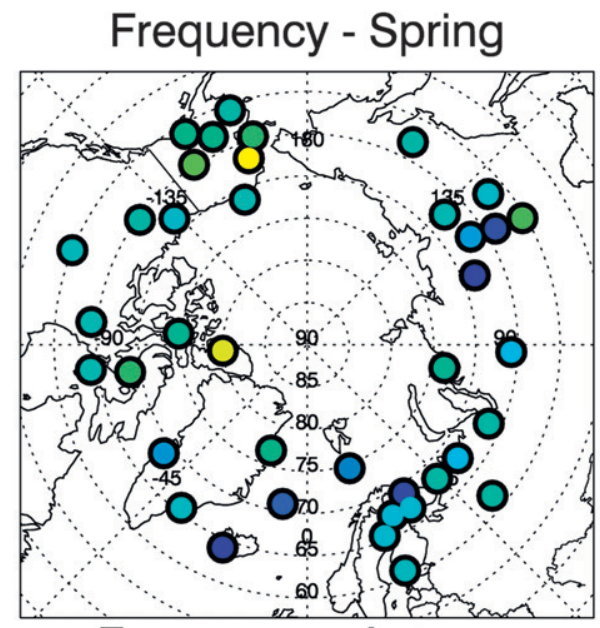

Frequency - Autumn

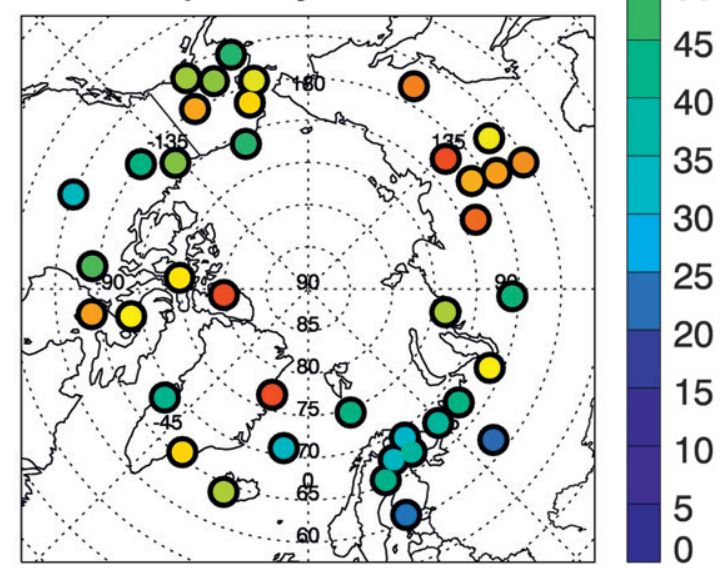

$\%$

100

95

90

85

80

75

70

65

60

55

50

45

40

35

30

25

20

15

10

0

FIG. 4. Seasonal variation of Arctic SBI frequency from 39 radiosonde stations during 1990-2009.

SBIs are found in $>80 \%$ of soundings, whereas spring and summer SBI frequencies are $30 \%-40 \%$ at most stations, with minimum frequency around $20 \%$ in all seasons. The distributions of SBI depth and intensity are similar. SBIs are deepest $(>800 \mathrm{~m})$ and most intense $(>15 \mathrm{~K})$ over Siberia in winter and autumn. Depth and intensity in spring and summer are relatively small, $<500 \mathrm{~m}$ and $7 \mathrm{~K}$, respectively, over the entire domain. Minimum SBI depth and intensity are at island stations in the Norwegian Sea in all four seasons.

Standard deviations of annual values (Fig. S4) of $f, \Delta z$, and $\Delta T$ are of order one-tenth of 20 -yr means. For SBI frequency, this interannual variability is smaller than the seasonal variations (Fig. 4). But for SBI $\Delta z$ and $\Delta T$, interannual and seasonal variability are comparable (Figs. S5 and S6). Interestingly, the interannual standard deviations are similar in magnitude to the structural uncertainties discussed in section $2 \mathrm{f}$.

Although not well sampled by the twice-daily radiosonde schedule, a possible diurnal variation (0000 versus
1200 UTC contrast) in SBI frequency is discernible (Fig. 5). SBIs are more frequent in the Western Hemisphere at 1200 UTC and in the Eastern Hemisphere at 0000 UTC. The maps of SBI depth and intensity for the two standard observation times do not show systematic patterns. As will be shown in the next section, the frequency patterns have a strong seasonal structure, and the diurnal differences in SBI frequency are mainly in summer, with SBI frequency decreasing with increasing solar elevation angle.

Clear gradients in frequency, depth, and intensity are found in the Eastern Hemisphere, increasing from low values over the Norwegian Sea eastward toward the East Siberian Sea (Fig. 3). Similar patterns were identified by Kahl et al. (1992) and Serreze et al. (1992), who attribute the frequent, strong SBIs over Siberia to cold-air drainage at valley locations combined with subsidence associated with the strong wintertime Siberian anticyclone, while less frequent, weaker SBIs around Northern Europe and the Norwegian 
Frequency - 1200 UTC

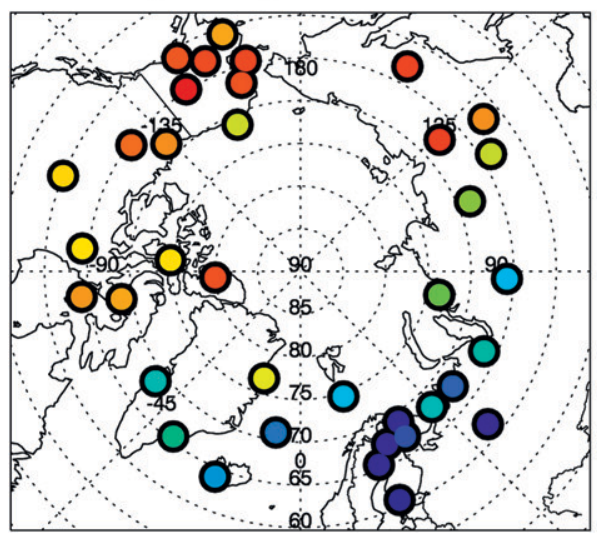

Depth - 1200 UTC

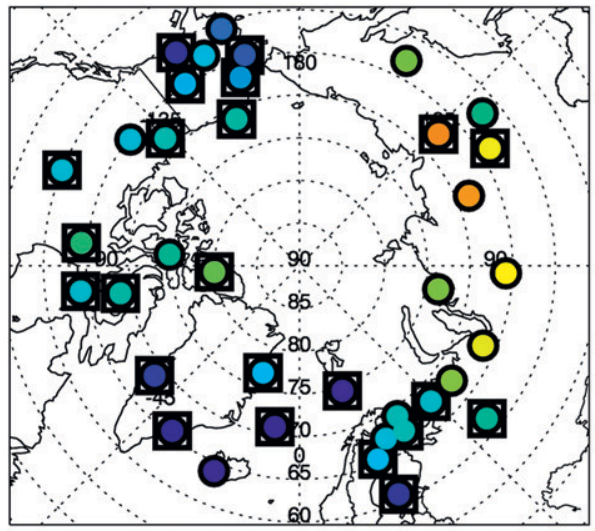

Intensity - 1200 UTC

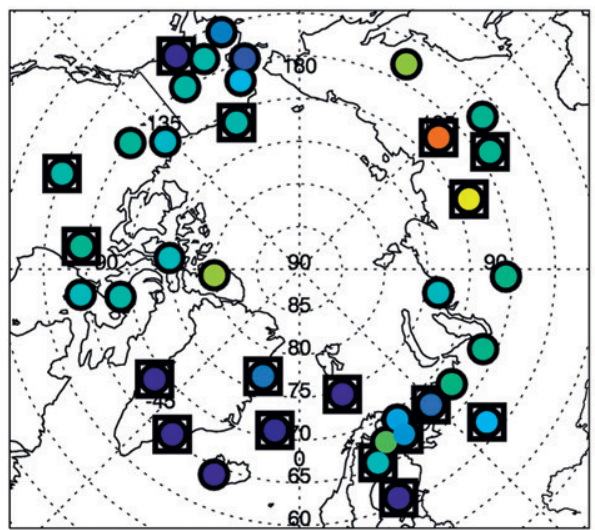

Frequency - 0000 UTC \%

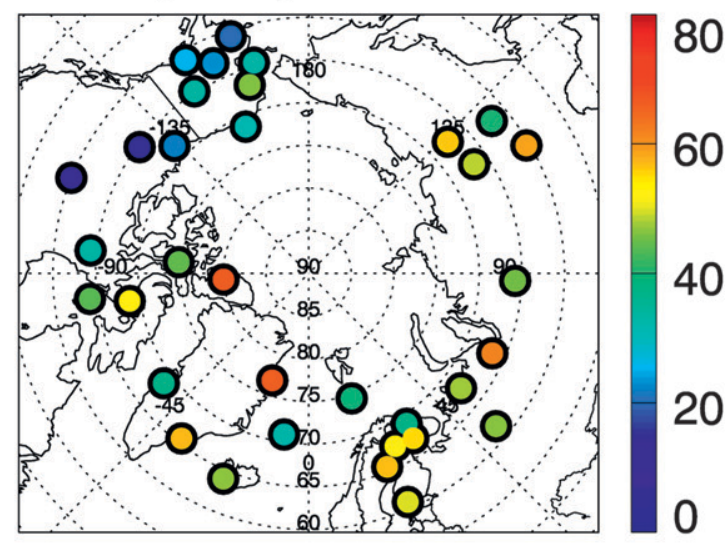

Depth - 0000 UTC 100 m

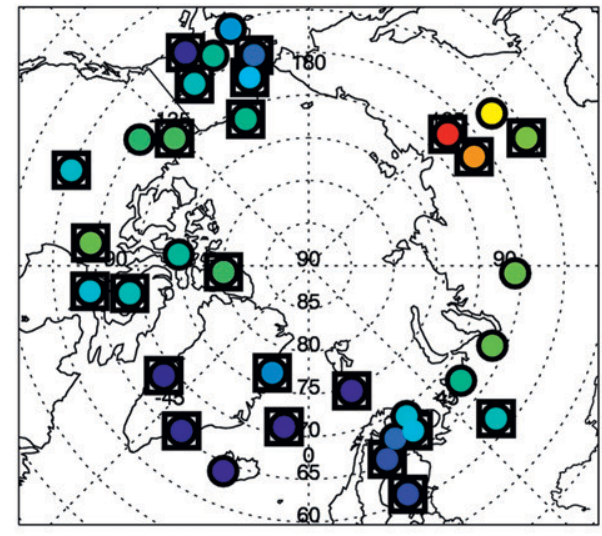

10

8

6

4

2

0

$\mathrm{K}$

15

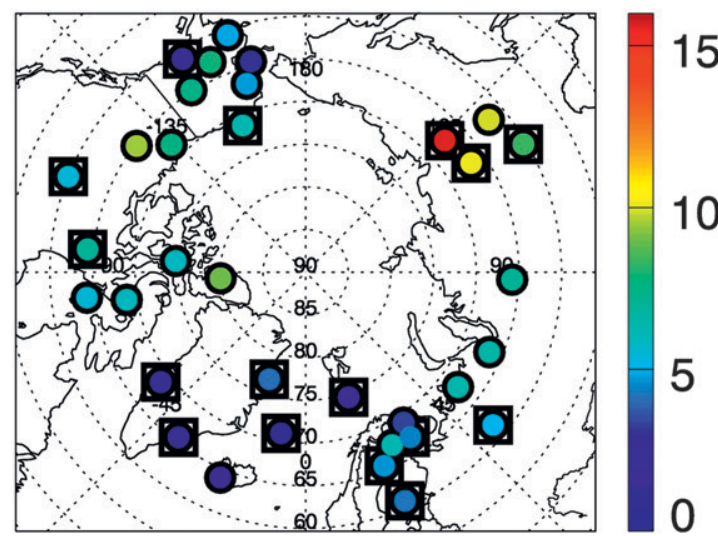

FIG. 5. Maps of mean Arctic SBI (top) frequency, (middle) depth, and (bottom) intensity from (left) 37 radiosonde stations at 1200 UTC and (right) 34 stations at 0000 UTC during 1990-2009. Squares denote stations with inhomogeneous SBI depth and intensity records.

Sea are caused by the proximity of open water, cyclonic activity, and the effects of cloud cover on the longwave flux. The eastward gradients in frequency (Fig. 3) are more pronounced in autumn and winter than in spring and summer (Fig. 4), which supports this interpretation.

To examine covariations among these three SBI properties, Table 1 and Figs. 6 and 7 show the results of 
TABLE 1. Spatial pattern correlations among SBI frequency $(f)$, depth $(\Delta z)$, and intensity $(\Delta T)$. All correlation coefficients are based on paired values of long-term (monthly or annual) means from 39 Arctic stations. Results in square brackets are not statistically significant at the $95 \%$ confidence level.

\begin{tabular}{lccc}
\hline \hline & $r(f, \Delta z)$ & $r(f, \Delta T)$ & $r(\Delta z, \Delta T)$ \\
\hline Jan & 0.44 & 0.49 & 0.94 \\
Feb & 0.52 & 0.53 & 0.93 \\
Mar & 0.55 & 0.52 & 0.84 \\
Apr & 0.57 & 0.53 & 0.83 \\
May & {$[0.13]$} & 0.50 & 0.55 \\
Jun & {$[-0.06]$} & 0.59 & {$[0.30]$} \\
Jul & {$[-0.21]$} & 0.59 & {$[0.24]$} \\
Aug & {$[-0.19]$} & {$[0.34]$} & {$[0.21]$} \\
Sep & {$[0.27]$} & {$[0.24]$} & 0.53 \\
Oct & 0.40 & 0.46 & 0.79 \\
Nov & 0.50 & 0.49 & 0.94 \\
Dec & 0.43 & 0.47 & 0.92 \\
Annual & 0.44 & 0.47 & 0.84 \\
\hline
\end{tabular}

correlation analyses. Spatial correlations (Table 1) based on monthly and annual climatological station values of SBI frequency, depth, and intensity are almost all positive. Correlations based on annual values all exceed 0.4 , with annual $r(\Delta z, \Delta T)=0.84$. Thus in regions with more frequent SBIs, they tend to be deeper and stronger. Spatial correlations between depth and intensity, $r(\Delta z, \Delta T)$, are higher than those involving frequency, $r(f, \Delta z)$ and $r(f, \Delta T)$, as expected from the similar patterns of SBI depth and intensity in Figs. 3, 5, S5, and S6. There is an obvious seasonal variation in the correlations, with higher values in winter and autumn months than the rest of the year, particularly for $r(\Delta z$, $\Delta T)$ and $r(f, \Delta z)$. Again, this supports the notion that deep, intense SBIs form in winter in the regions where they are more frequent.

Temporal correlation coefficients are presented in Figs. 6 and 7, which also show the correlation between surface temperature (sfc) and SBI properties. Most correlation coefficients for monthly SBI properties (Fig. 6) are close to +1 , indicating that all three SBI properties exhibit similar annual cycles at most stations, except stations over the Norwegian Sea. This result is also consistent with the results shown in Figs. 4, S5, and S6. In contrast, most correlation coefficients between surface temperature and SBI properties are near -1 . Higher surface temperatures
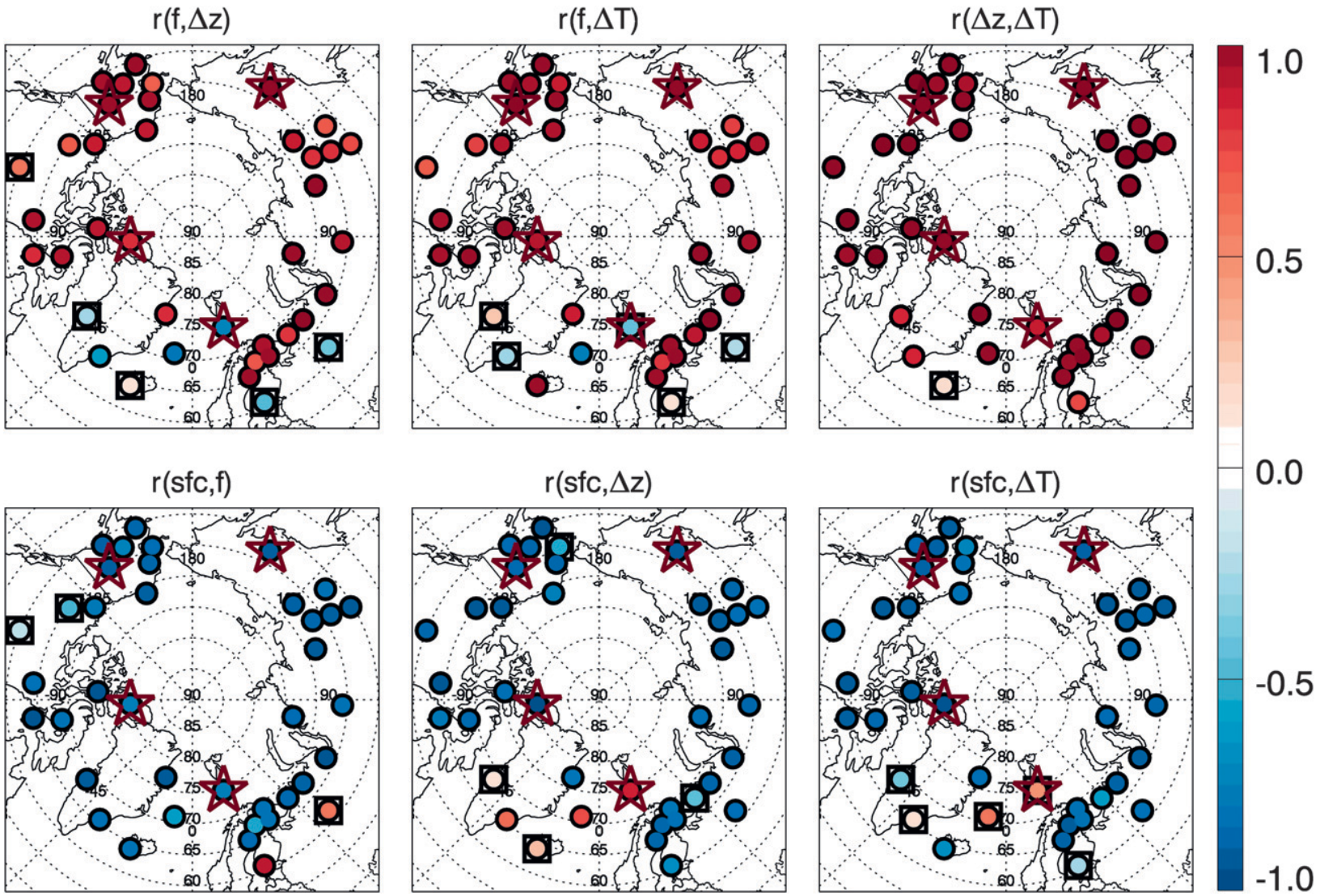

0.0

FIG. 6. Maps of temporal (annual cycle) correlation coefficients computed from paired series of 12 monthly-mean values of SBI frequency $(f)$, depth $(\Delta z)$, intensity $(\Delta T)$, and surface temperature (sfc) at each Arctic station. Results with squares are not statistically significant at the $95 \%$ confidence level. Red stars identify stations whose mean annual cycles are shown in Fig. 12. 

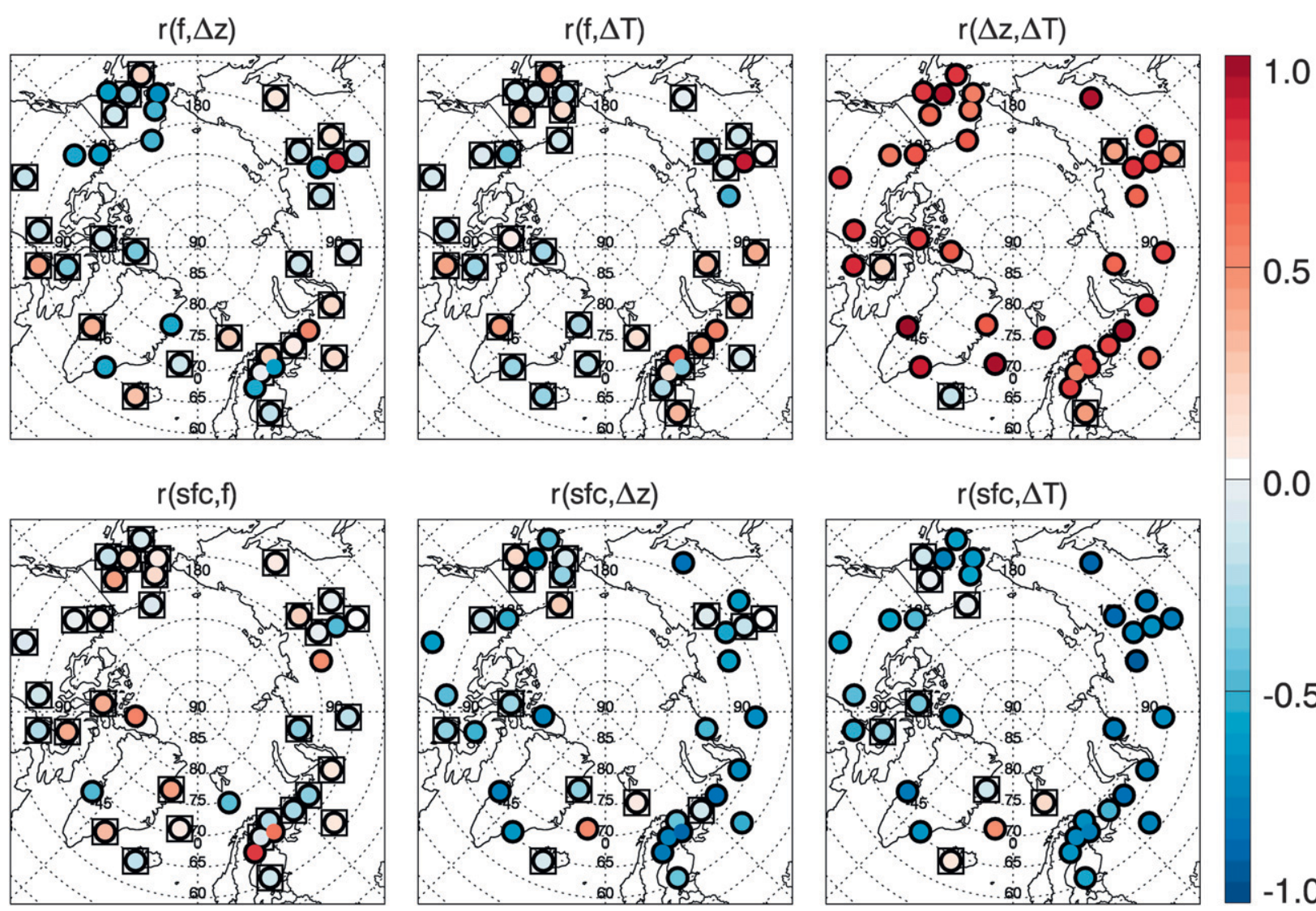

0.0

FIG. 7. Maps of interannual correlation coefficients computed from paired series of 20 annual-mean values (for 1990-2009) of SBI frequency $(f)$, depth $(\Delta z)$, intensity $(\Delta T)$, and surface temperature (sfc) at 39 Arctic stations. Results with squares are not statistically significant at the $95 \%$ confidence level.

(in summer) are associated with less frequent, shallower, and weaker SBIs, which is again consistent with the seasonal variations of SBI properties.

Correlations based on annual time series (Fig. 7) show a similar pattern as in Fig. 6, but with smaller $r$ values. At most stations, $r(\Delta z, \Delta T)>0.8$, but $r(f, \Delta z)$ and $r(f, \Delta T)$ are lower and not statistically significant at many stations. Correlations between surface temperature and SBI properties are generally negative but weaker than for the seasonal cycle (Fig. 6), and $r(\mathrm{sfc}, f)$ are close to 0 . Thus, years with higher than normal surface temperature have shallower and weaker SBIs, although SBI frequency shows little association with surface temperature.

\section{b. Arctic SBI climatology in climate models and reanalysis data}

Figures 8, 9,10, and 11 show comparisons between the radiosonde-based Arctic SBI climatology and those derived from the NCAR CAM3 and NOAA GFDL AM3 models and from the ERA-Interim reanalysis. Supplemental material (Figs. S7 and S8) provides additional comparisons.
The dominant seasonal patterns of SBI properties derived from the models and reanalysis are similar to the observational results (Figs. 8 and S7)-all show more frequent, deeper, and stronger SBIs in winter and autumn. However, there are notable differences in magnitudes. For example, Fig. 9 shows wintertime SBI depth and intensity. (Wintertime frequency is shown in Fig. 8 first row.) The ERA-Interim is in better accord with the observations for SBI frequency, which the two models underestimate over much of the domain, in all four seasons (Fig. 8). It is not surprising that the reanalysis, which assimilates observations, performs better than the unconstrained climate models. However, it is not clear which is more accurate in regions where radiosondes are not available, such as over the Arctic and North Atlantic Oceans.

The depths of SBIs in NCAR CAM3, GFDL AM3, and ERA-Interim are deeper, thinner, and similar compared with the radiosonde observations, respectively (Figs. 9 and S7). The deeper SBIs in NCAR CAM3 are consistent with that model's lower vertical resolution than the other datasets (section 2b). For SBI intensity, 

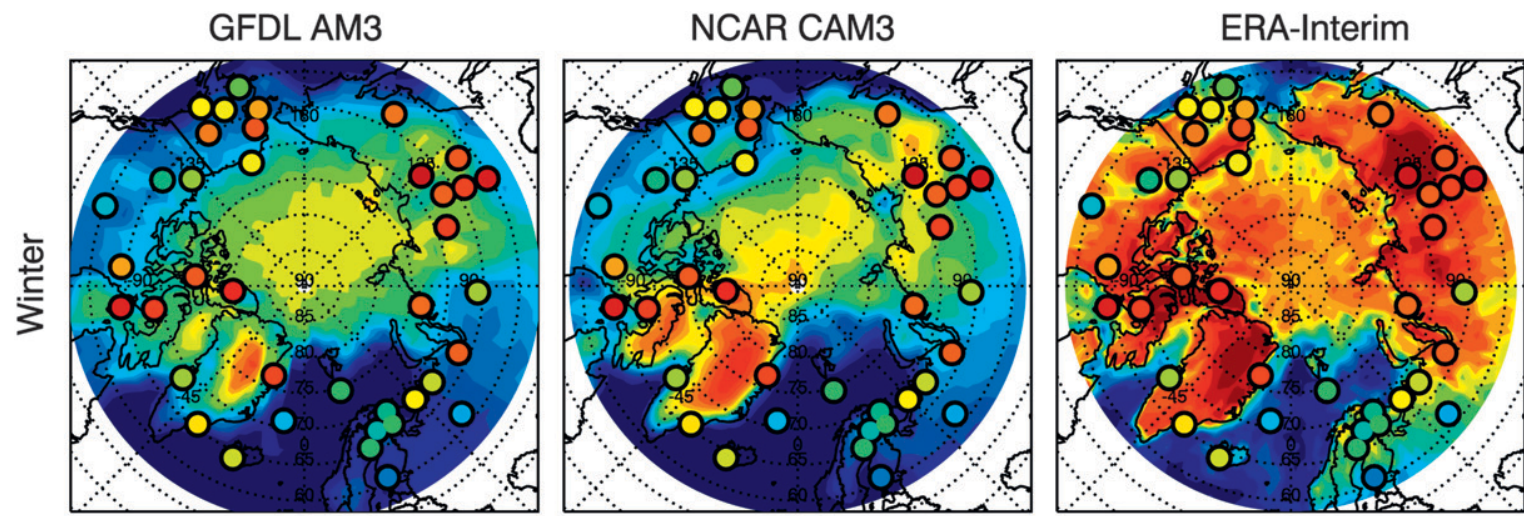

$\%$
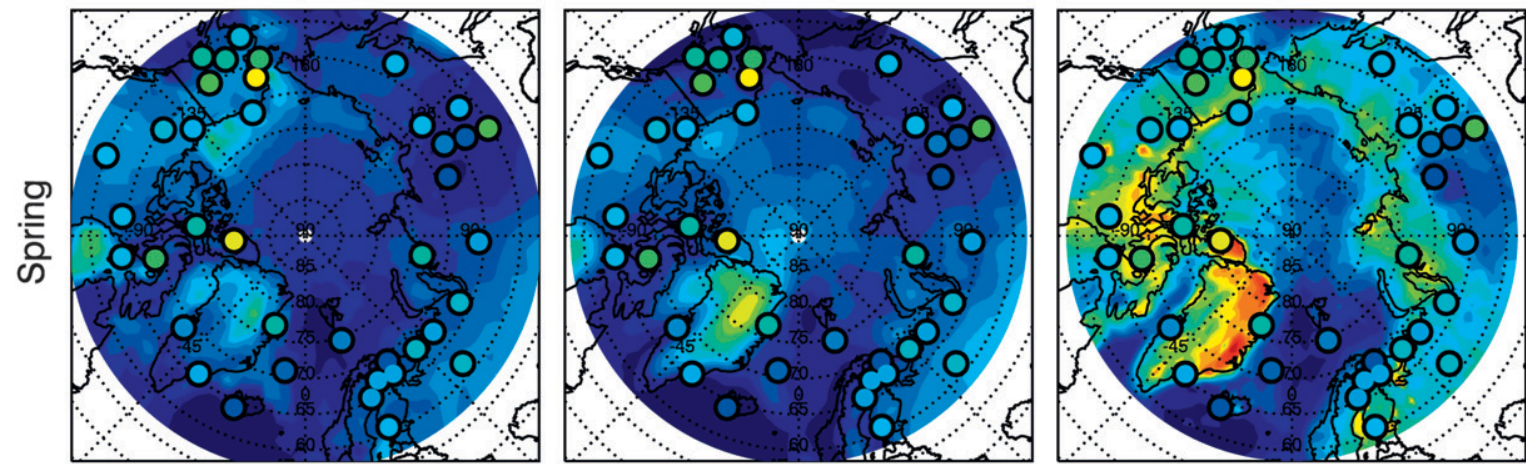

75
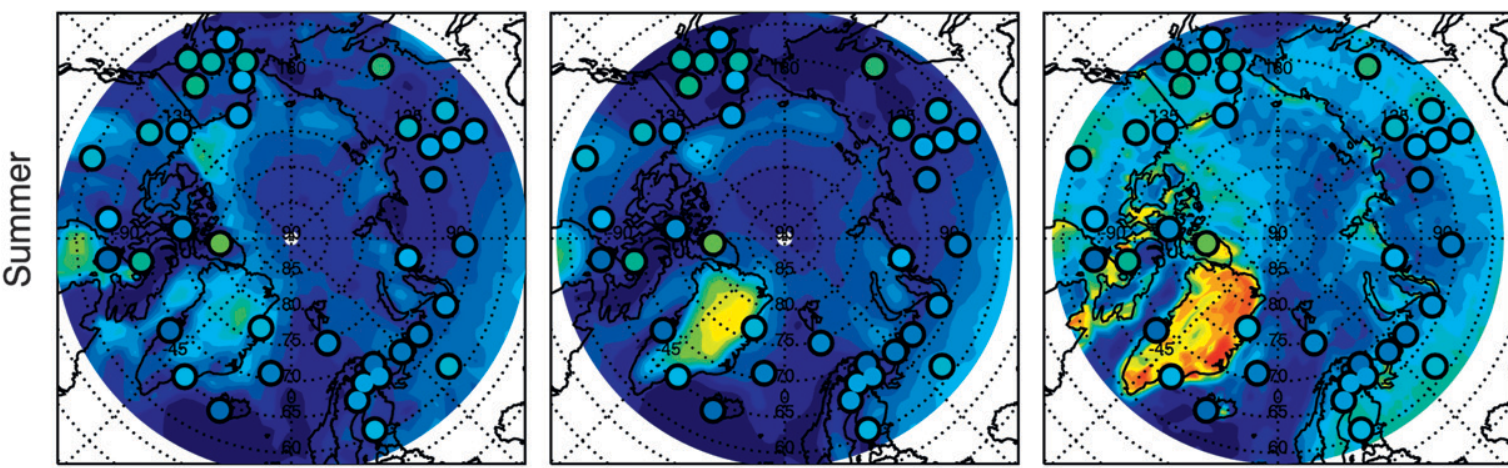

50
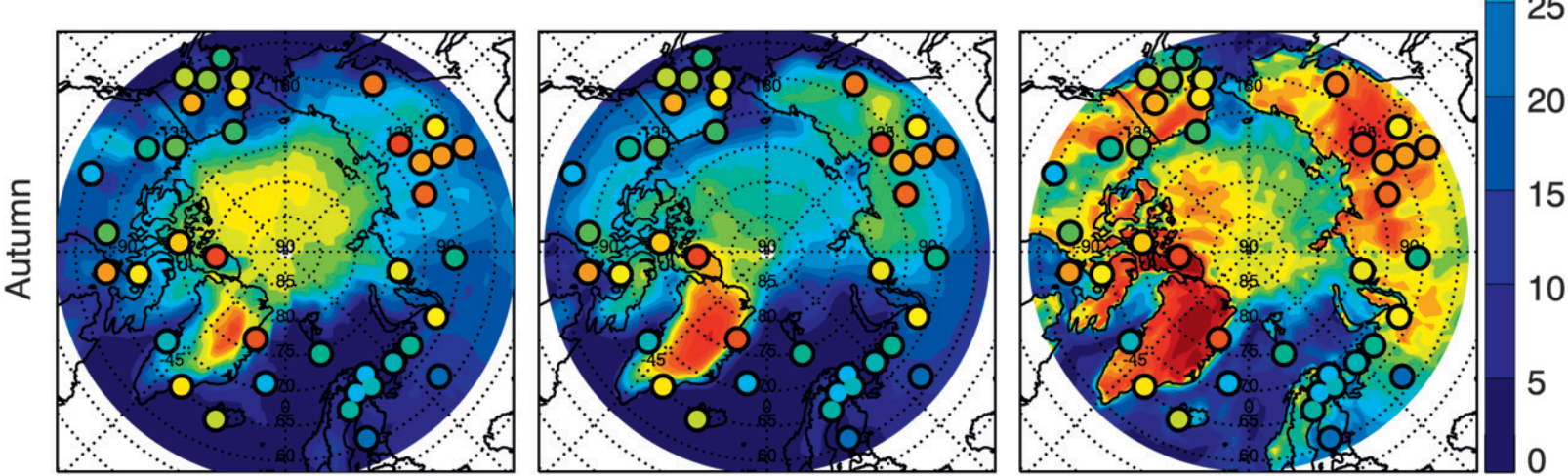

FIG. 8. Maps of mean seasonal SBI frequency over the Arctic from IGRA radiosonde observations (colored dots) and from the (left) GFDL AM3 model, (middle) NCAR CAM3 model, and (right) ERA-Interim reanalysis. Data periods are 1990-2007 for the climate models and 1990-2009 for ERA-Interim. 

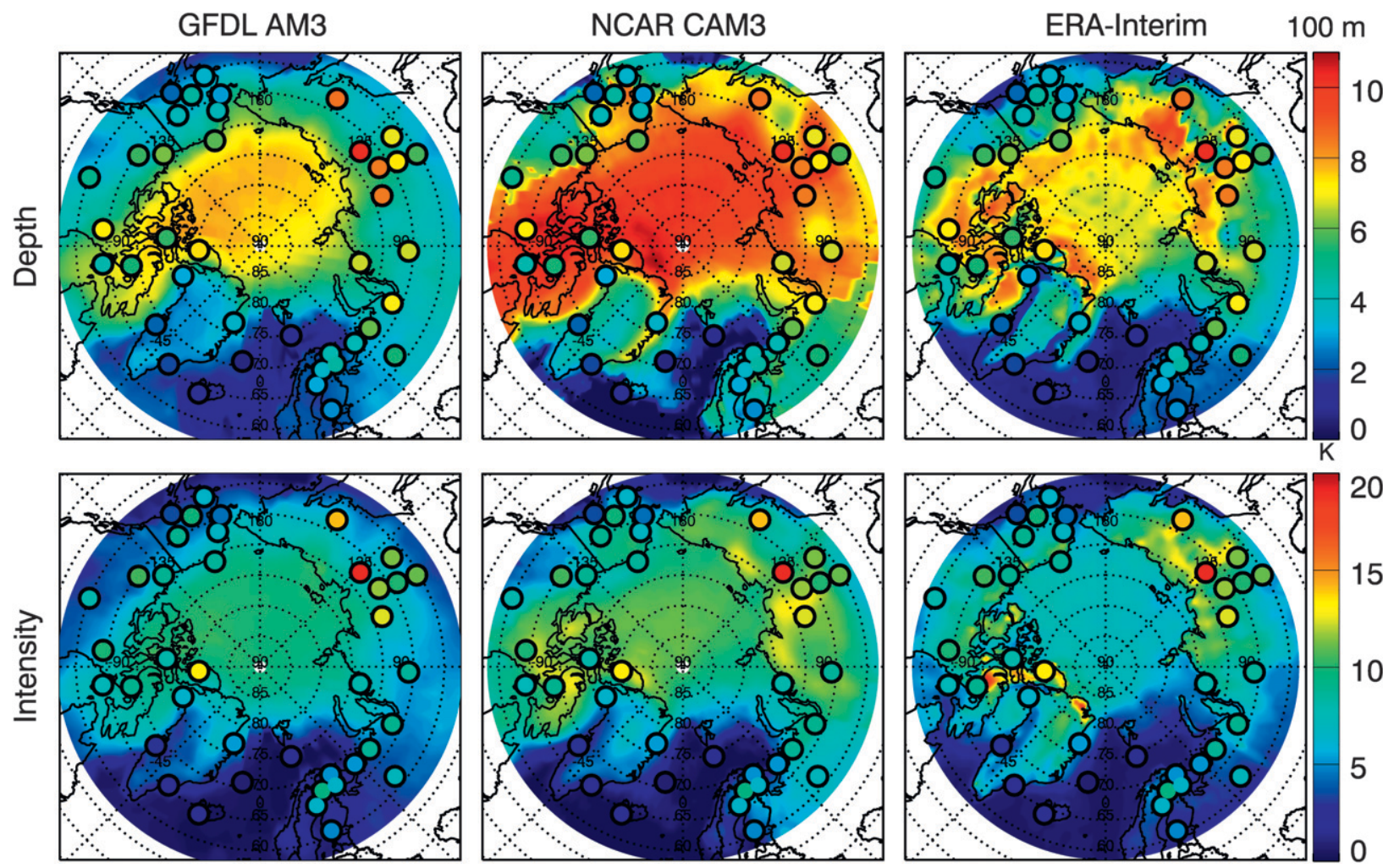

FIG. 9. Maps of winter Arctic SBI (top) depth and (bottom) intensity compared with observations (colored dots) in the (left) GFDL-AM3 and (middle) NCAR-CAM3 (middle) models, and in (right) ERA-Interim reanalysis data.

both models and the reanalysis show patterns and magnitudes that are quite consistent with the observations (Figs. 9 and S7), except the GFDL AM3, which simulates lower SBI intensities than observed. Over Siberia, this may be related to stations' valley locations not being well represented in the gridded model output.

Model depictions of diurnal variations of SBI properties are presented in Figs. 10, 11, and S8, where we have sampled the models at 0000 and 1200 UTC for direct comparison with the observations, despite the availability of 0600 and 1800 UTC model results. Climatological SBI frequency shows strong diurnal patterns, as seen by comparison of 0000 and 1200 averages (Fig. 10, which includes the radiosonde results shown in Fig. 5) and in maps of the 1200 minus 0000 UTC differences (Fig. 11, top row). The reanalysis is in better accord with the radiosondes than either climate model. However, although the GFDL AM3 and NCAR CAM3 underestimate the frequency over much of the Arctic domain at both observation times (Fig. 10), their depiction of the diurnal difference agrees with the radiosonde observations. Large frequency differences $(\sim \pm 50 \%)$ have coherent spatial patterns, with more frequent SBIs at 1200 UTC within about $90^{\circ}$ longitude of the international date line, and more frequent 0000 UTC SBIs within $95^{\circ}$ longitude east (but not west) of the Greenwich Meridian, on an annual mean basis (Fig. 11, top row). However, this pattern is driven by summertime conditions, with results for June (Fig. 11, middle row) showing even larger differences than the annual values, and December showing near-zero differences (Fig. 11, bottom row). In Arctic summer (day), solar elevations angles are higher at 0000 UTC near the date line, and solar heating reduces the tendency for SBI formation. The larger differences east of the date line and east of Greenwich can be understood in terms of the sun's path in the sky; those regions have already seen the sun's highest elevation by the time of the 0000 or 1200 UTC observations, compared with comparable regions west of those longitudes, which will see the sun's highest elevation after observation times. In contrast to the frequency patterns (Figs. 10 and 11), SBI depth and intensity at the two observation times are fairly similar, as seen both in the observations (Fig. 5) and in the models and reanalysis (Fig. S8).

The analysis above has focused on gross spatial and temporal patterns, but careful examination of the mapped results reveals local variations that merit our attention, particularly because of the strong local topographic and microclimatological controls on SBI features (as compared with the free troposphere above 

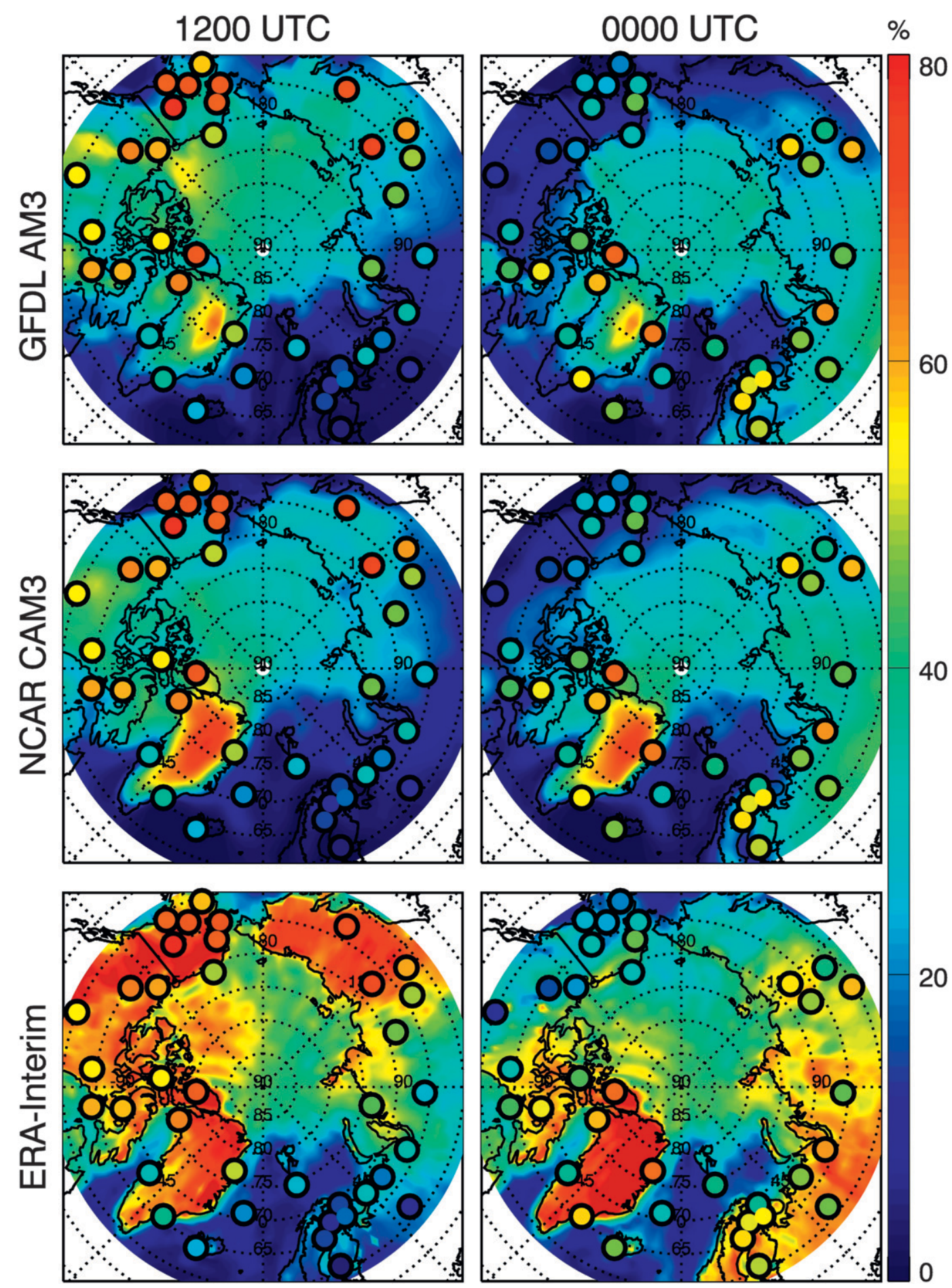

FIG. 10. Maps of mean annual SBI frequency at (left) 1200 and (right) 0000 UTC from radiosonde observations (colored dots) and from the (top) GFDL AM3, (middle) NCAR CAM3, and (bottom) ERA-Interim reanalysis. Data periods are 1990-2007 for the climate models and 1990-2009 for ERA-Interim.

the boundary layer). The mean annual cycles of SBI properties, at both 0000 and 1200 UTC, at four specific stations are shown in Fig. 12. The climate model and reanalysis results for the grid point closest to the station are also shown. The stations are as follows, in order of decreasing latitude: Eureka, on the Canadian Arctic archipelago; Bjornoya, Norway, an island in the Svalbard archipelago of the western Barents Sea; Fairbanks, 

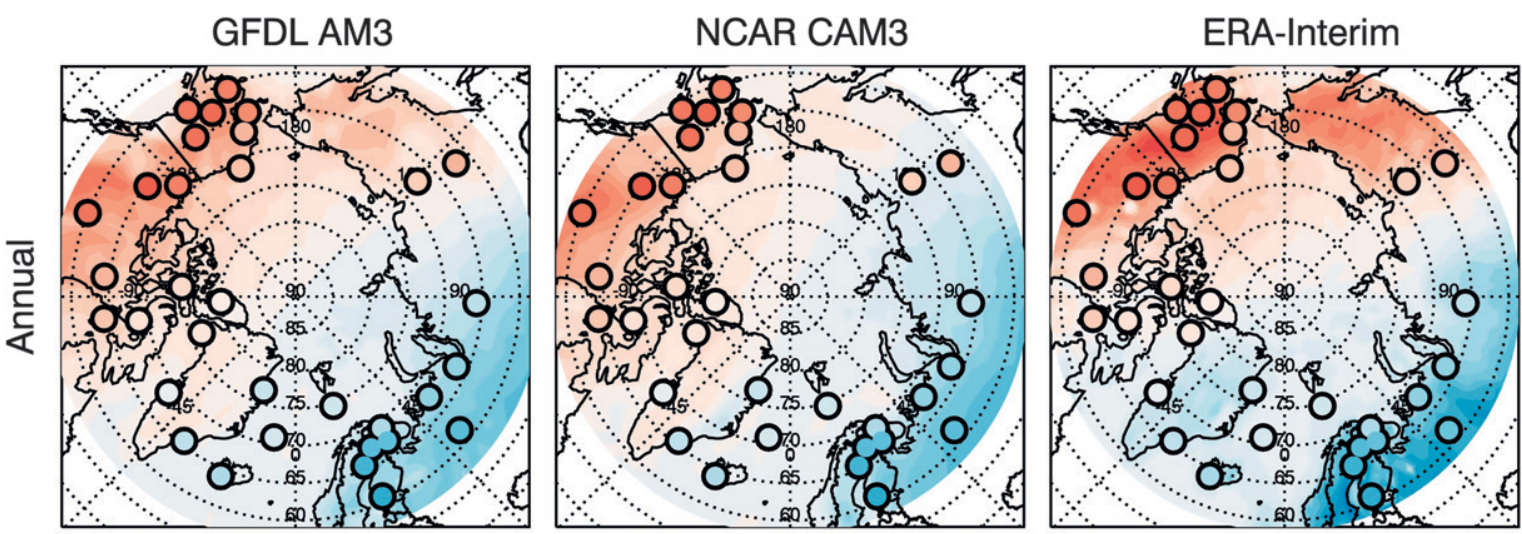

$\%$
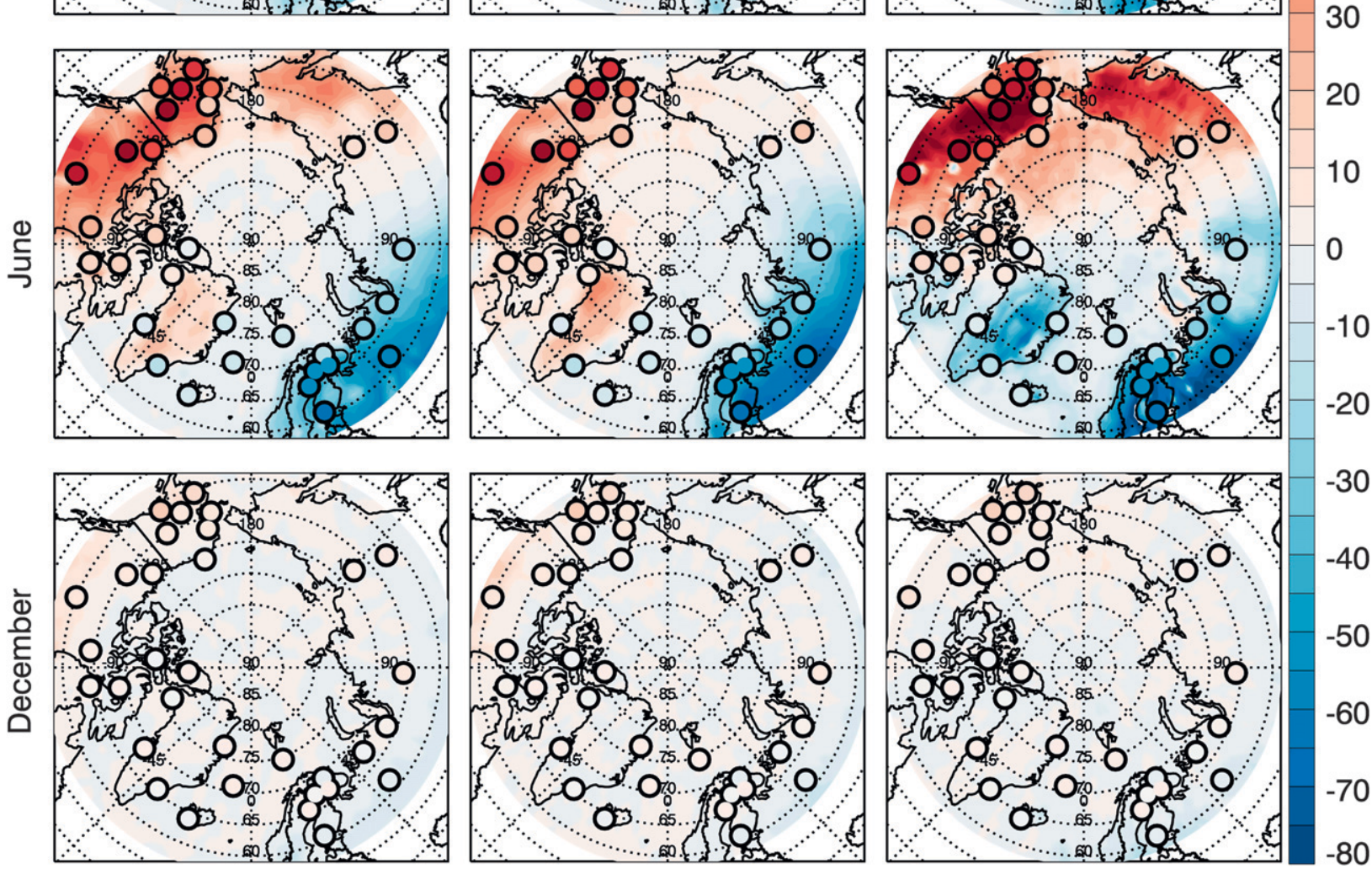

FIG. 11. Differences between 1200 and 0000 UTC Arctic SBI frequency based on (top) annual (all months) data, (middle) June data, and (bottom) December data as observed by radiosondes (colored dots) and as simulated by the (left) GFDL AM3, (middle) NCAR-CAM3, and (right) ERA-Interim reanalysis.

Alaska, an inland valley station; and Seimchan, Russia, by the Seimchan River. See Fig. 6 for station locations.

The main feature of Fig. 12 is the spatial variability, both of the observed seasonal cycles and of the model simulations. For example, the observed seasonal variation of SBI frequency shows wintertime maximum and summertime minimum at all four stations (Fig. 12, first column on left), but the amplitude is much larger at Eureka, Fairbanks, and Seimchan than at Byjornoya. The correlation results in Fig. 6 are consistent with the observed annual cycles shown in Fig. 12. The models and reanalysis capture the seasonality at Eureka fairly well, but they are much less successful at the other three stations and some even have an out-of-phase annual cycle in SBI frequency. Discrepancies between the radiosonde results (black lines) and the reanalysis (blue lines) suggest that other assimilated data and/or model physics sometimes override the assimilated radiosonde observations in ERA-Interim's depiction of SBIs.

Biases among the four datasets are also evident in Fig. 12. The NCAR CAM3 (green lines) simulates deeper SBIs than the other three datasets at all four stations. The GFDL AM3 (red lines) tends to produce shallower and less intense SBIs than NCAR CAM3 and ERA-Interim, 

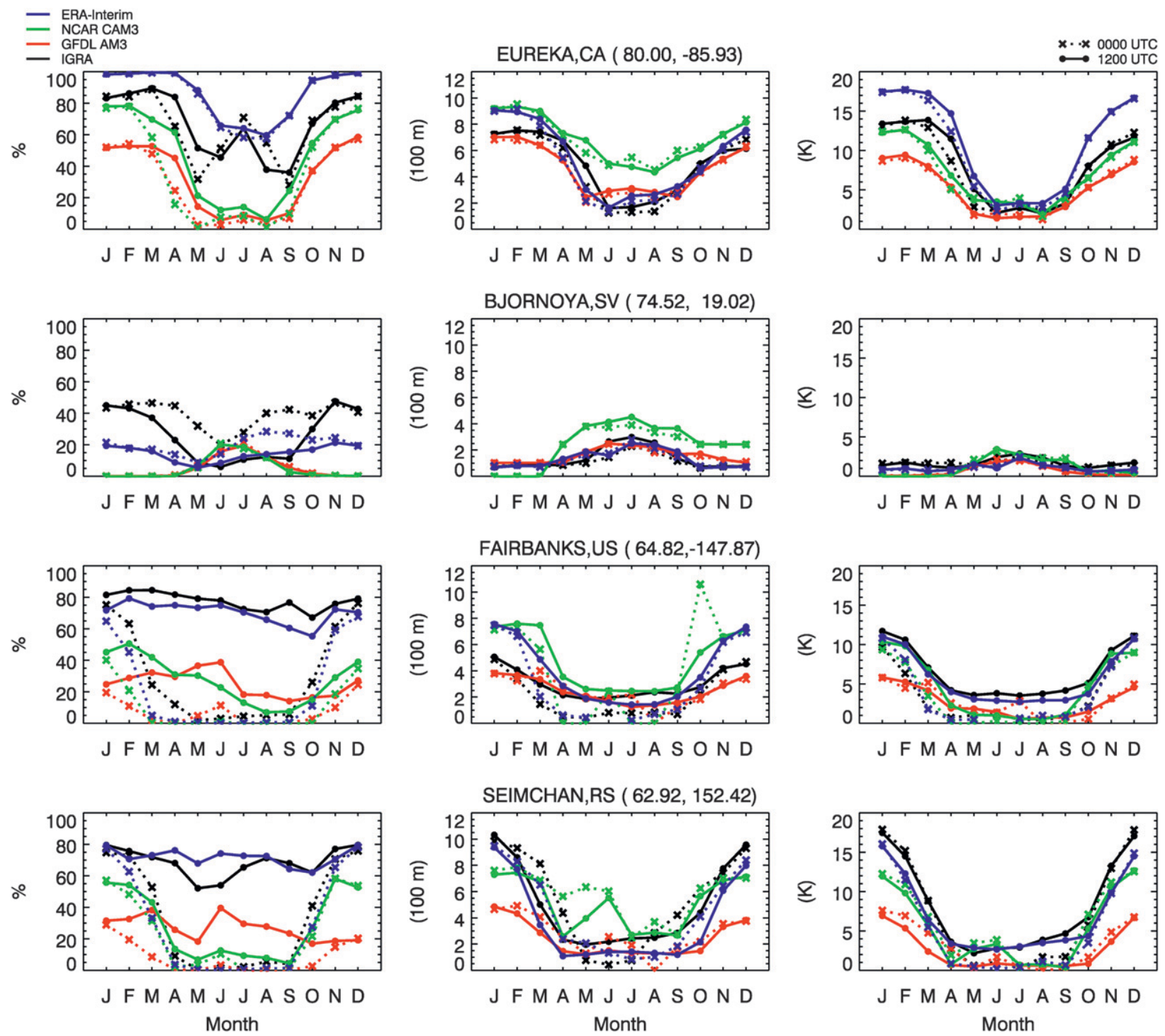

FIG. 12. Monthly variation of SBI (left) frequency, (middle) depth, and (right) intensity at four stations: Eureka, Bjornoya, Fairbanks, and Seimchan. Station locations are shown in Fig. 6; coordinates are given in Table S1. Results from four datasets are represented by four colors: IGRA (black), GFDL AM3 (red), NCAR CAM3 (green), and ERA-Interim (blue). Solid lines denote 1200 UTC and dotted lines denote 0000 UTC.

but none of the three consistently outperforms the others in its consistency with the observations. The poor simulation of the observed seasonal cycle of SBI frequency at Bjornoya may be related to the spatial resolution of the models and reanalysis. Bjornoya is near a strong gradient in sea surface temperature associated with a narrow warm North Atlantic current, which likely inhibits the development of SBIs. This feature may not be well represented in the models and may explain the seasonal variation of SBI depth and intensity at Bjornoya, which is different from the other three stations.

The biases among the datasets have some systematic structure, as seen in Fig. 13, which compares the models to the radiosonde results using scatterplots. In each plot of seasonal values of one of the three SBI characteristics (frequency, depth, and intensity), the three models are differentiated by color, and results from five Arctic regions (Canada, Europe, Greenland, Russia, and the United States) are differentiated by symbol shape. The tendency for ERA-Interim (blue symbols) to overestimate SBI frequency is clear, as is the NCAR CAM3 (green) and GFDL AM3 (red) tendencies to underestimate it. In winter and autumn, when SBIs are more frequent, deeper, and more intense, and when there is a larger range of values among the stations, the model biases are relatively smaller. For inversion depth, the NCAR CAM3 

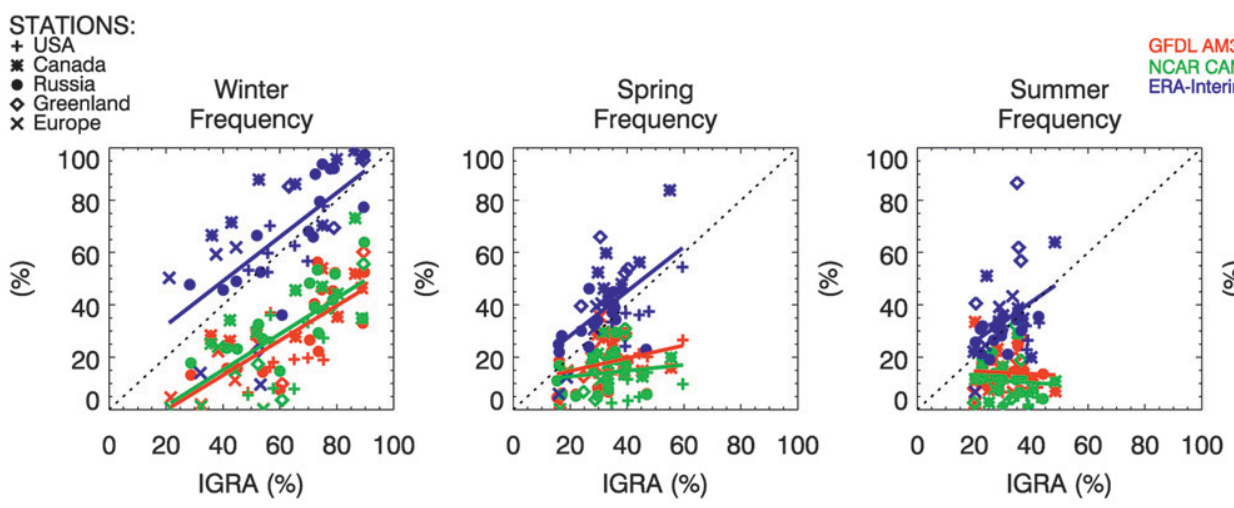

DL AM3 - 1990-2007
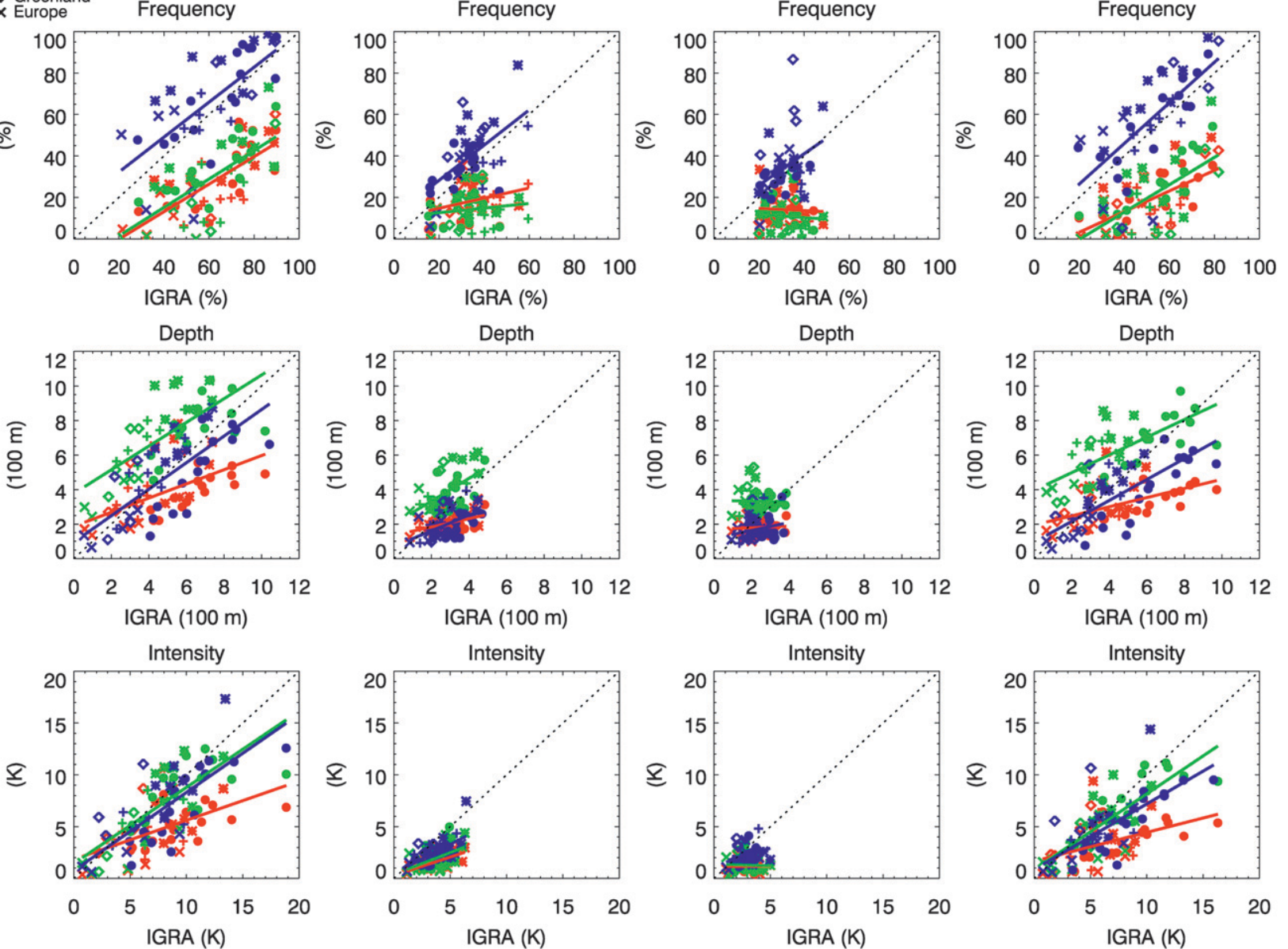

FIG. 13. Scatterplot comparisons of mean seasonal Arctic SBI (top) frequency, (middle) depth, and (bottom) intensity as observed by radiosondes (IGRA) and as depicted in the GFDL AM3 (red), NCAR CAM3 (green), and ERA-Interim reanalysis (blue). Stations are grouped by the following regions: Canada (asterisk), Europe $(\times)$, Greenland (diamond), Russia (dot), and the United States (plus). The thick solid lines show linear regression results, and dotted lines are 1:1 slopes.

overestimates at most stations and ERA-Interim results are close to observed, while GFDL AM3 SBIs are shallower, especially at Russian stations. This may be related to the prescribed sea surface temperatures (SSTs) in the GFDL AM3 constraining the results at coastal stations more than at inland Russian stations, and the model's large 2-m temperature warm bias over the northern latitude land areas.

\section{c. SBI climatology for Antarctica}

The radiosonde network provides a much less detailed picture of the Antarctic atmosphere than the Arctic, with less than one-quarter the number of stations, most along the continent's coasts, many taking only one observation per day and some operating only part of the year. Of the two inland Antarctic stations in IGRA, one
(Amundsen-Scott, $90^{\circ} \mathrm{S}, 0^{\circ}$ ) has inhomogeneous records and the other (Vostok, $78^{\circ} \mathrm{S}, 107^{\circ} \mathrm{E}$ ) has very incomplete records. After considering data homogeneity and continuity issues, we retain only six coastal stations (Table S2), which severely compromises our ability to describe the SBI climatology in the south Polar region.

Radiosonde observations indicate that, compared with the Arctic, SBIs over the Antarctic are generally more frequent, shallower, and weaker (Fig. S10). Median Antarctic SBI $f, \Delta z$, and $\Delta T$ are $58 \%, 197 \mathrm{~m}$, and $2.6 \mathrm{~K}$, respectively. However, both regions have similar seasonal patterns. As in the Arctic, SBIs over Antarctica are more frequent, deeper, and stronger in winter and autumn than in spring and summer (Fig. S9). Figure 14 compares the three model results with the radiosonde observations for winter, and Fig. 15 show scatterplots for 

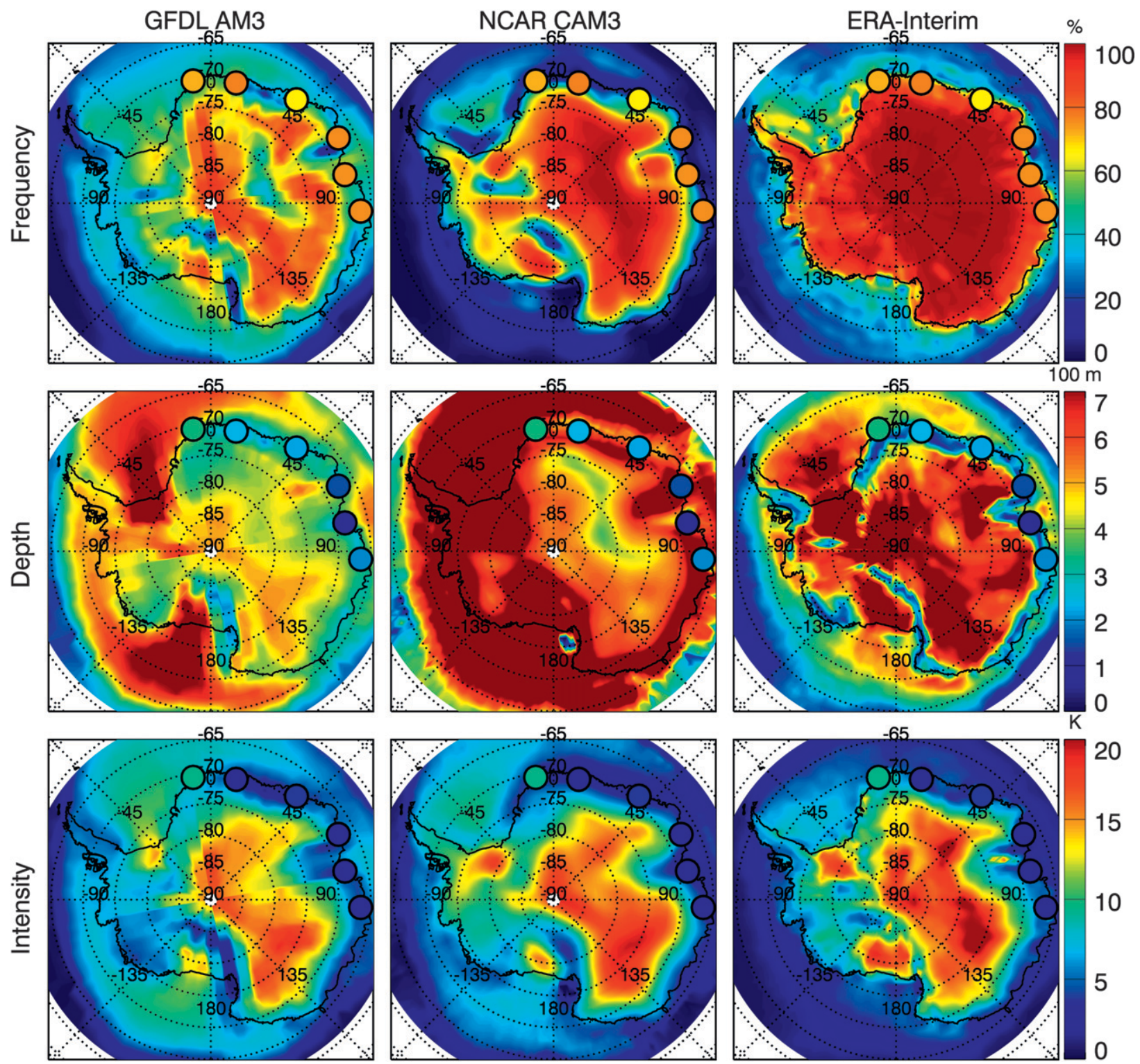

FIG. 14. Maps of winter Antarctic SBI (top) frequency, (middle) depth, and (bottom) intensity compared with observations (colored dots) in the (left) GFDL AM3 and (middle) NCAR-CAM3 models and in (right) ERA-Interim reanalysis data.

all four seasons. The two climate models and the reanalysis show SBIs in the Antarctic interior are more common than at the coasts, with seasonal frequencies close to $100 \%$ in winter and autumn, in accord with previous analyses (Phillpot and Zillman 1970; Connolley 1996). Compared with the coast, the interior is colder, drier, and less windy, all features that are conducive to SBI formation.

There is more seasonal variation in SBIs along the coasts, with summer and spring frequencies $<50 \%$. While ERA-Interim captures this seasonality, the two climate models tend to underestimate the observed frequency (Fig. 15). As seen in Fig. 14, this may be related to the strong model gradient in SBI frequency between the Antarctic continent and the surrounding ocean. The climate models simulate coastal conditions more similar to the oceanic than the continental climatology.

At the East Antarctic coastal stations, SBIs are $\sim 200 \mathrm{~m}$ deep throughout the year, while along the Weddell Sea coast $\Delta z \approx 300 \mathrm{~m}$ all year. The GFDL AM3 and ERA-Interim reanalysis capture observed SBI depth better than the NCAR CAM3, which overestimates $\Delta z$, especially in autumn and winter (Figs. 14 and 15). However, the better agreement between the GFDL AM3 results and the observations is due to a more complex spatial pattern (Figs. 14 and S9). 
STATIONS:

- Weddell Sea coas

$\times$ East Antarctic coast
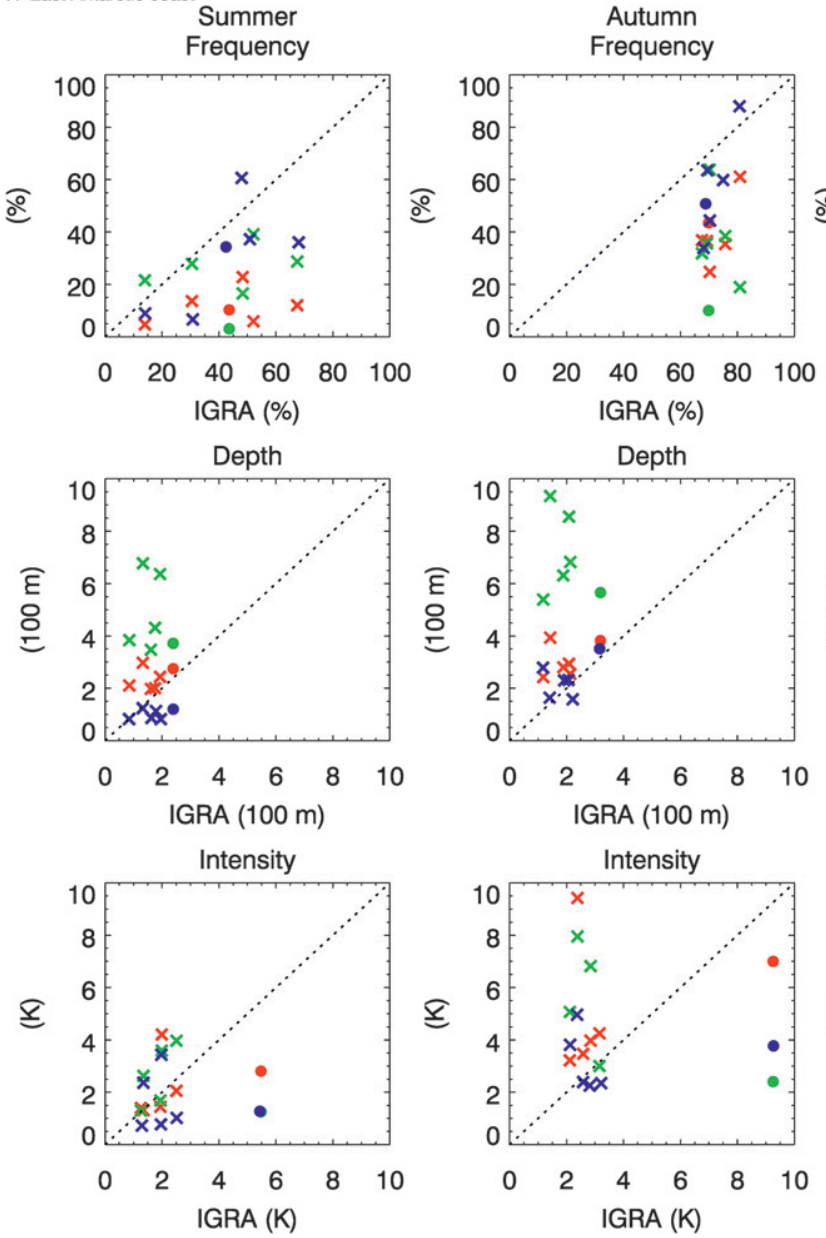
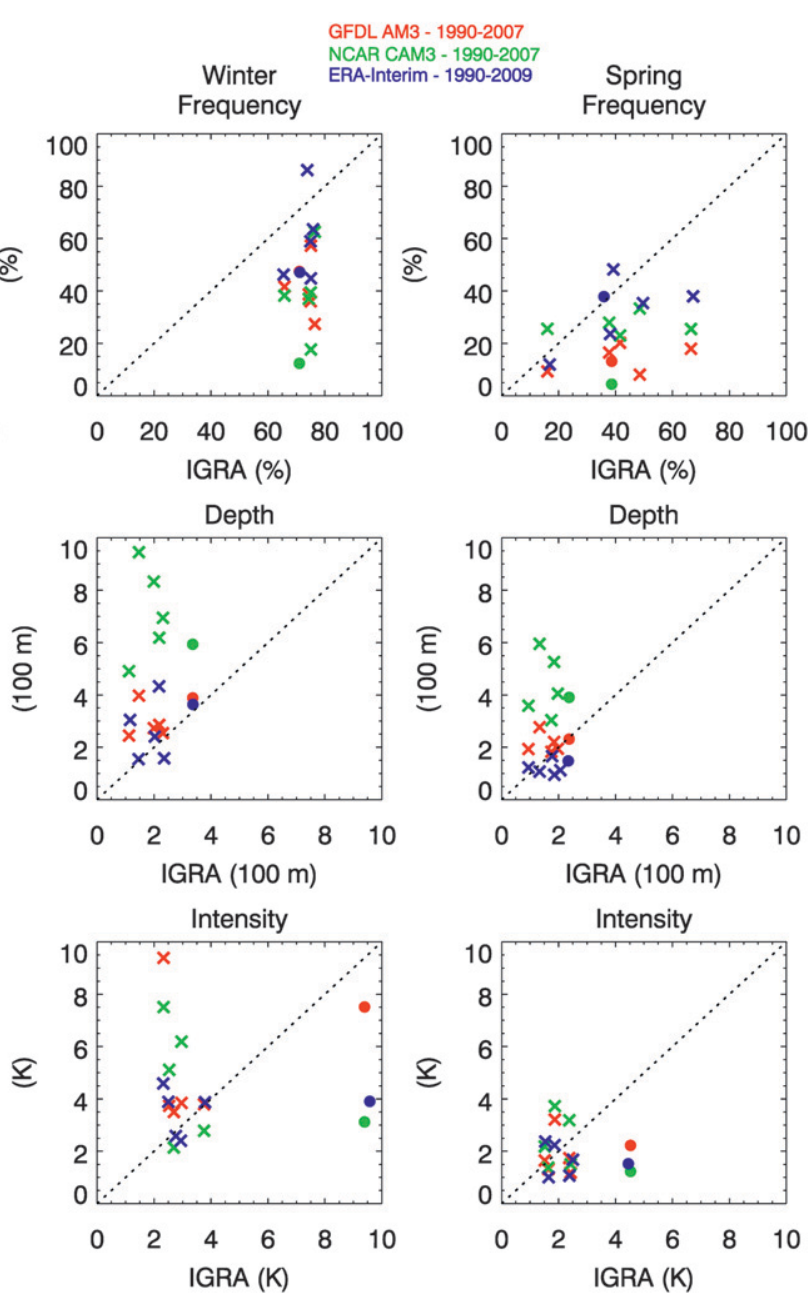

FIG. 15. As in Fig. 13, but for Antarctica, and the symbols are for East Antarctic coast $(\times)$ and Weddell Sea coast $(\bullet)$

At most East Antarctic coastal stations $\Delta T$ is around $3 \mathrm{~K}$, but at the Weddell Sea coast in winter and autumn $\Delta T \approx 10 \mathrm{~K}$ (Figs. 15 and S9). The models capture these patterns fairly well but underestimate the SBI intensity along the Weddell Sea coast (Fig. 15).

Comparing Figs. 13 and 15 for the Arctic and Antarctic suggests better model/observation agreement in the Arctic, where there is less scatter in the data. However, this may be due to the much better sampling in the Arctic and the fact that most of the Antarctic stations are in the transitional coastal region, where land-sea surface differences and topographic gradients must influence SBI formation in the atmosphere and in the models.

\section{Conclusions}

Analysis of Arctic and Antarctic surface-based inversions (SBIs) in a carefully selected set of radiosonde data, two climate models, and one reanalysis dataset has revealed climatological patterns in SBI frequency of occurrence, depth (from the surface to the SBI top), and intensity (temperature difference within the SBI). The main findings are as follows.

1) Changes in the vertical resolution of archived radiosonde data lead to inhomogeneities in estimates of SBI intensity and depth and, to a lesser extent, estimates of SBI frequency. Such inhomogeneities, as well as large data gaps, make many Arctic and Antarctic station records not suitable for climatological analysis.

2) Although we have not attempted a complete analysis of structural uncertainty in SBI statistics, some uncertainties are comparable in magnitude to the interannual variability about the 20 -yr climatological mean values of SBI frequency, depth, and intensity.

3) SBIs are generally more frequent, deeper, and more intense in winter and autumn (polar night) than in spring and summer (polar day) over both polar regions.

4) In the Arctic, SBI frequency, depth, and intensity appear to increase eastward from the Norwegian Sea 
toward the East Siberian Sea in winter and autumn, possibly in association with increasing continentality.

5) In summer, solar elevation differences in local radiosonde launch times at different longitudes explain geographic patterns of SBI frequency differences between the two observation times, 0000 and 1200 UTC. Such differences are not observed in winter, polar night.

6) The radiosonde network is much sparser in the Antarctic than in the Arctic, and most observations are along the Antarctic coast. SBIs along the Weddell Sea coast are deeper and more intense than those at East Antarctic coast.

7) Compared with the radiosonde observations, the NCAR CAM3 and NOAA GFDL AM3 climate models and the ERA-Interim reanalysis data show generally similar seasonal patterns and spatial distributions of the three SBI characteristics examined. However, biases among the datasets are found, and there are spatial differences in the bias patterns. SBI intensities derived from the four datasets are in a good agreement. The GFDL AM3 has a larger bias in SBI depth (with shallower SBIs than observed) at most Russian stations and Antarctic stations. The NCAR CAM3 shows deeper SBIs at most Arctic and Antarctic stations (perhaps due to its lower vertical resolution), while ERA-Interim results are close to observed. Despite its assimilation of radiosonde observations, ERAInterim reanalysis overestimates SBI frequency at most stations, while the climate models underestimate it at most stations. These biases are smaller in winter and autumn than in summer and spring.

8) Over most of the Arctic (but not over the North Atlantic) the annual cycles of SBI frequency, depth, and intensity are positively correlated, and these SBI characteristics are negatively correlated with surface temperature. Interannual variability shows less association among SBI characteristics, although SBI intensity is positively correlated with SBI depth and negatively correlated with surface temperature on an interannual basis.

This study is the first comprehensive analysis of SBI features in the polar regions in observations and models. Our analysis was limited to two models, and we hope the observational data will be used in future investigations involving other models. The radiosonde, reanalysis, and model datasets used herein are available as supplemental material. A companion study (Zhang and Seidel 2011) will examine long-term (multidecadal) variations and trends of Arctic SBI characteristics.

Acknowledgments. We thank Journal of Climate Editor Robert Wood and two anonymous referees, who provided thorough and thoughtful reviews of this paper. Jennifer
Kay, Brian Medeiros, and Sungsu Park (NCAR), Chi Ao (Jet Propulsion Laboratory), and Julian Wang (NOAA) offered insightful comments on this study. Y. Zhang is a National Research Council Postdoctoral Associate at NOAA's Air Resources Laboratory. NCAR is sponsored by the National Science Foundation. C. Deser and R. Tomas gratefully acknowledge funding from the NSF Office of Polar Programs.

\section{REFERENCES}

Andreas, E. L, 1980: Estimation of heat and mass fluxes over Arctic leads. Mon. Wea. Rev., 108, 2057-2063.

- and B. Murphy, 1986: Bulk transfer coefficients for heat and momentum over leads and polynyas. J. Phys. Oceanogr., 16, 1875-1883.

— spheric jets and inversions over the Western Weddell Sea. Bound.-Layer Meteor., 97, 459-486.

Anquetin, S., C. Guilbaud, and J.-P. Chollet, 1998: The formation and destruction of inversion layers within a deep valley. J. Appl. Meteor., 37, 1547-1560.

Barrie, L. A., J. W. Bottenheim, R. C. Schnell, P. J. Crutzen, and R. A. Rasmussen, 1988: Ozone destruction and photochemical reactions at polar sunrise in the lower Arctic atmosphere. Nature, 334, 138-141.

Boé, J., A. D. Hall, and X. Qu, 2009: Current GCMs' unrealistic negative feedback in the Arctic. J. Climate, 22, 4682-4695.

Bourne, S. M., U. S. Bhatt, J. Zhang, and R. Thoman, 2010: Surfacebased temperature inversions in Alaska from a climate perspective. Atmos. Res., 95, 353-366, doi:10.1016/j.atmosres.2009.09.013.

Bowling, S., 1986: Climatology of high-latitude air pollution as illustrated by Fairbanks and Anchorage, Alaska. J. Climate Appl. Meteor., 25, 22-34.

Bradley, R. S., F. T. Keimig, and H. F. Diaz, 1992: Climatology of surface-based inversions in the North American Arctic. J. Geophys. Res., 97, 15 699-15 712.

,$- \ldots$, and _ 1993: Recent changes in the North American Arctic boundary layer in winter. J. Geophys. Res., 98, 88518858.

Busch, N., U. Ebel, H. Kraus, and E. Schaller, 1982: The structure of the subpolar inversion-capped ABL. Arch. Meteor. Geophys. Bioklimatol., 31A, 1-18.

Collins, W. D., and Coauthors, 2006: The formulation and atmospheric simulation of the Community Atmosphere Model version 3 (CAM3). J. Climate, 19, 2144-2161.

Connolley, W. M., 1996: The Antarctic temperature inversion. Int. J. Climatol., 16, 1333-1342.

Curry, J., 1983: On the formation of polar continental air. J. Atmos. Sci., 40, 2278-2292.

Deser, C., R. Tomas, M. Alexander, and D. Lawrence, 2010: The seasonal atmospheric response to projected Arctic sea ice loss in the late twenty-first century. J. Climate, 23, 333-351.

Devasthale, A., U. Willén, K.-G. Karlsson, and C. G. Jones, 2010: Quantifying the clear-sky temperature inversion frequency and strength over the Arctic Ocean during summer and winter seasons from AIRS profiles. Atmos. Chem. Phys., 10, 55655572, doi:10.5194/acp-10-5565-2010.

Donner, L. J., and Coauthors, 2011: The dynamical core, physical parameterizations, and basic simulation characteristics of the atmospheric component of the GFDL Global Coupled Model CM3. J. Climate, 24, 3484-3519. 
Durre, I., and X. Yin, 2008: Enhanced radiosonde data for studies of vertical structure. Bull. Amer. Meteor. Soc., 89, 1257-1262.

- - R. S. Vose, and D. B. Wuertz, 2006: Overview of the integrated global radiosonde archive. J. Climate, 19, 53-68.

Gaffen, D. J., 1994: Temporal inhomogeneities in radiosonde temperature records. J. Geophys. Res., 99, 3667-3676.

Graversen, R. G., T. Mauritsen, M. Tjernström, E. Källén, and G. Svensson, 2008: Vertical structure of recent Arctic warming. Nature, 451, 53-56.

Hosler, C. R., 1961: Low-level inversion frequency in the contiguous United States. Mon. Wea. Rev., 89, 319-339.

Hudson, S. R., and R. E. Brandt, 2005: A look at the surface-based temperature inversion over the Antarctic Plateau. J. Climate, 18, 1673-1696.

Kadygrov, E. N., A. S. Viazankin, E. R. Westwater, and K. B. Widener, 1999: Characteristics of the low-level temperature inversion at the North Slope of Alaska on the base of microwave remote sensing data. Proc. Ninth ARM Science Team Meeting, San Antonio, TX, Department of Energy, 1-7.

Kahl, J. D., 1990: Characteristics of the low-level temperature inversion along the Alaskan Arctic coast. Int. J. Climatol., 10, 537-548.

_ M. C. Serreze, and R. C. Schnell, 1992: Tropospheric lowlevel temperature inversions in the Canadian arctic. Atmos.Ocean, 30, 511-529.

Kalnay, E., and Coauthors, 1996: The NCEP/NCAR 40-Year Reanalysis Project. Bull. Amer. Meteor. Soc., 77, 437-471.

Kay, J. E., and A. Gettelman, 2009: Cloud influence on and response to seasonal Arctic sea ice loss. J. Geophys. Res., 114, D18204, doi:10.1029/2009JD011773.

Lanzante, J. R., 1996: Resistant, robust and non-parametric techniques for the analysis of climate data: Theory and examples including applications to historical radiosonde station data. Int. J. Climatol., 16, 1197-1226.

Liu, Y., and J. Key, 2003: Detection and analysis of clear sky, lowlevel atmospheric temperature inversions with MODIS. J. Atmos. Oceanic Technol., 20, 1727-1737.

Mahesh, A., V. P. Walden, and S. G. Warren, 1997: Radiosonde temperature measurements in strong inversions: Correction for thermal lag based on an experiment at South Pole. J. Atmos. Oceanic Technol., 14, 45-53.

Malingowski, J. A., D. Atkinson, J. Cherry, E. Stevens, and D. Morton, 2010: Using weather balloon launches to understand the Fairbanks surface-based temperature inversion lifecycle. Preprints, 15th Symp. on Meteorological Observation and Instrumentation, Atlanta, GA, Amer. Meteor. Soc., 7.5. [Available online at http://ams.confex.com/ams/90annual/ techprogram/paper_161743.htm.]
Mernild, S. H., and G. E. Liston, 2010: The influence of air temperature inversion on snowmelt and glacier mass balance simulations, Ammassalik Island, Southeast Greenland. J. Appl. Meteor. Climatol., 49, 47-67.

Oleson, K. W., and Coauthors, 2004: Technical description of the Community Land Model (CLM). NCAR Tech. Note NCAR/ TN-461+STR, 173 pp.

Onogi, K., and Coauthors, 2007: The JRA-25 Reanalysis. J. Meteor Soc. Japan, 85, 369-432.

Pavelsky, T., J. Boé, A. Hall, and E. Fetzer, 2011: Atmospheric inversion strength over polar oceans in winter regulated by sea ice. Climate Dyn., 36, 945-955, doi:10.1007/s00382-010-0756-8.

Phillpot, H. R., and J. W. Zillman, 1970: The surface temperature inversion over the Antarctic Continent. J. Geophys. Res., $\mathbf{7 5}$ 4161-4169.

Seidel, D. J., C. O. Ao, and K. Li, 2010: Estimating climatological planetary boundary layer heights from radiosonde observations: Comparison of methods and uncertainty analysis. J. Geophys. Res., 115, D16113, doi:10.1029/2009JD013680.

Serreze, M. C., J. D. Kahl, and R. C. Schnell, 1992: Low-level temperature inversions of the Eurasian Arctic and comparisons with Soviet drifting station data. J. Climate, 5, 599613.

Simmons, A., S. Uppala, D. Dee, and S. Kobayashi, 2007: ERAInterim: New ECMWF reanalysis product from 1989 onwards. ECMWF Newsletter, Vol. 110, ECMWF, Reading, United Kingdom, 25-35.

Stone, R. S., and J. D. Kahl, 1991: Variations in boundary layer properties associated with clouds and transient weather disturbances at the South Pole during winter. J. Geophys. Res., 96, 5127-5144.

Tjernström, M., and R. G. Graversen, 2009: The vertical structure of the lower Arctic troposphere analysed from observations and the ERA-40 reanalysis. Quart. J. Roy. Meteor. Soc., 135, 431-443, doi:10.1002/qj.380.

Uppala, S. M., and Coauthors, 2005: The ERA-40 Re-Analysis. Quart. J. Roy. Meteor. Soc., 131, 2961-3012.

Walden, V. P., A. Mahesh, and S. G. Warren, 1996: Comment on "Recent changes in the North American Arctic boundary layer in winter." J. Geophys. Res., 101, 7127-7134.

WMO, cited 2008: Guide to meteorological instruments and methods of observation. 7th ed. World Meteorological Organization. [Available online at http://www.wmo.int/pages/prog/ www/IMOP/publications/CIMO-Guide/CIMO_Guide-7th_ Edition-2008.html.]

Zhang, Y., and D. J. Seidel, 2011: Challenges in estimating trends in Arctic surface-based inversions from radiosonde data. Geophys. Res. Lett., 38, L17806, doi:10.1029/2011GL048728. 